Review Article

\title{
A Structural Review of Thermoelectricity for Fuel Cell CCHP Applications
}

\author{
Nganyang Paul Bayendang, Mohamed Tariq Kahn, and Vipin Balyan \\ Department of Electrical, Electronics and Computer Engineering, Cape Peninsula University of Technology, Cape Town, South Africa \\ Correspondence should be addressed to Vipin Balyan; vipin.balyan@rediffmail.com
}

Received 26 December 2019; Revised 21 May 2020; Accepted 29 May 2020; Published 21 July 2020

Academic Editor: Hao Wu

Copyright (c) 2020 Nganyang Paul Bayendang et al. This is an open access article distributed under the Creative Commons Attribution License, which permits unrestricted use, distribution, and reproduction in any medium, provided the original work is properly cited.

\begin{abstract}
This article starts by introducing the ongoing South Africa electricity crisis followed by thermoelectricity, in which eighteen miscellaneous applicable case studies are structurally analysed in detail. The aim is to establish best practices for the R\&D of an efficient thermoelectric (TE) and fuel cell (FC) CCHP system. The examined literature reviews covered studies that focused on the thermoelectricity principle, highlighting TE devices' basic constructions, TEGs and TECs as well as investigations on the applications of thermoelectricity with FCs, whereby thermoelectricity was applied to recover waste heat from FCs to boost the power generation capability by $\sim 7-10 \%$. Furthermore, nonstationary TEGs whose generated power can be increased by pulsing the DC-DC power converter showed that an output power efficiency of $8.4 \%$ is achievable and that thicker TEGs with good area coverage can efficiently harvest waste heat energy in dynamic applications. TEG and TEC exhibit duality and the higher the TEG temperature difference, the more the generated power-which can be stabilised using the MPPT technique with a $1.1 \%$ tracking error. A comparison study of TEG and solar energy demonstrated that TEG generates more power compared to solar cells of the same size, though more expensively. TEG output power and efficiency in a thermal environment can be maximised simultaneously if its heat flux is stable but not the case if its temperature difference is stable. The review concluded with a TEC LT-PEM-FC hybrid CCHP system capable of generating $2.79 \mathrm{~kW}$ of electricity, $3.04 \mathrm{~kW}$ of heat, and $26.8 \mathrm{~W}$ of cooling with a total efficiency of $\sim 77 \%$ and fuel saving of $43.25 \%$. The presented research is the contribution brought forward, as it heuristically highlights miscellaneous thermoelectricity studies/parameters of interests in a single manuscript, which further established that practical applications of thermoelectricity are possible and can be innovatively applied together with FC for efficient CCHP applications.
\end{abstract}

\section{Introduction}

Faced with ongoing electrical energy and power crisis in South Africa [1] and Africa in general, this paper extensively examines various research on thermoelectricity in order to determine, develop, and apply best practices for the devise of an efficient TE fuel cell hybrid power energy system for home and commercial combined cooling heating and power (CCHP) applications. As stated in [1], the research problems and fuel cells have been reasonably covered in detailed. Thermoelectricity, as per [2-52], is a thermal and or electrical process, in which a material based on its thermal and or electrical properties, can either generate heat or cold depending on the voltage polarity across the material or this same material is capable of generating electricity from heat, when there is a temperature difference $(\Delta T)$ on the material (technically known as a thermocouple) surfaces. Furthermore, there are three effects governing thermoelectricity commonly called thermoelectric effects, which are (i) the Seebeck effect (named after the discoverer, Thomas Seebeck), which is the generation of electricity from heat and the devices that enable such a process are popularly known as thermoelectric generators (TEG); (ii) the Peltier effect, (named after the discoverer, Jean Peltier), which is, depending on the applied voltage polarity, is the generation of cold from electricity, or when the same applied voltage polarity is reversed, is the generation of heat from electricity, and the devices that enable such a process are popularly known as thermoelectric 
coolers (TEC); and (iii) the Thomson effect (named after the discoverer, William Thomson or popularly known as Lord Kelvin) is the generation or absorption of heat when voltage is applied across a uniform material that has a temperature difference along its length, and depending on the flow of the electric current, the Thomson effect could be positive or negative. This Thomson effect is reversible and as a result, is different from Joule or Ohmic heating-which is an irreversible generation of heat when an electric current flows through an electrical conductor. The Thomson effect is usually negligible in practise (cannot be harnessed to produce the desired practical effect), and as a result, practical thermoelectricity is normally focused on the Seebeck and Peltier effects, and therefore, thermoelectricity can be practically defined as a reversible two-way or triple display of the same thermoelectrical process, known as the Peltier-Seebeck effect. According to the literature, thermoelectricity can be practically applied to (i) cogenerate electricity and/or (ii) provides thermal management (cooling and or heating). In [33], the electrical and thermal conductivities are related through the WiedemannFranz law by

$$
k_{e}=L_{\mathrm{o}} \sigma T,
$$

where $k_{e}$ is the thermal conductivity charge carrier contribution, $L_{\mathrm{o}}$ is a constant known as the Lorenz number $\left(2.44 \times 10^{-8} \mathrm{~W} \Omega \mathrm{K}^{-2}\right), \sigma$ is the electrical conductivity, and $T$ is the absolute temperature in Kelvin. Furthermore, the thermoelectric materials are categorised based on their dimensionless figure of merit, $z T$, defined by

$$
z T=\frac{S^{2} \sigma T}{k},
$$

where $S$ is the Seebeck voltage per unit of temperature in Kelvin, $\sigma$ is the electrical conductivity, $k$ is the thermal conductivity, and $T$ is the absolute temperature in Kelvin $(273.15 \mathrm{~K})$ or $0^{\circ} \mathrm{C}$.

The TE device maximum efficiency $\left(\eta_{\max }\right)$ determined by $Z T$ (different from $z T$ ), is given by:

$$
\begin{aligned}
\eta_{\max } & =\eta \frac{\sqrt{1+Z \bar{T}}-1}{\sqrt{1+Z \bar{T}}+\left(T_{c} / T_{h}\right)}, \text { where } \eta \\
& =\frac{\Delta T}{T_{h}} \text { is the Carnot efficiency and } \bar{T}=\frac{T_{h}+T_{c}}{2},
\end{aligned}
$$

where $Z T$ is the TEG dimensionless figure of merit, $\Delta T$ is the temperature difference between $T_{h}$ and $T_{c} ; Z \bar{T}$ is the device dimensionless figure of merit at temperature $\bar{T}$ while $T_{h}$ and $T_{c}$ are, respectively, the device hot and cold side temperature. When $Z T=z T$, the relationship becomes

$$
Z=z=\frac{S^{2} \sigma}{K},
$$

where $Z=z$ is the figure of merit in $\mathrm{K}^{-1}$ and $S^{2} \sigma$ is known as the TEG electrical power factor.
The TEG thermal/conversion efficiency $\left(\eta_{\mathrm{TEG}}\right)$ is defined by

$$
\eta_{\mathrm{TEG}}=\frac{\mathrm{TEG}_{\text {Pout }}}{Q_{h}},
$$

where $T E G_{\text {Pout }}$ is the generated TEG output power and $Q_{h}$ the heat absorbed at TEG hot junction.

$$
\begin{aligned}
\mathrm{TEG}_{\text {Pout }} & =n\left[S I\left(T_{\mathrm{h}}-T_{\mathrm{c}}\right)-\left(I^{2} R\right)\right], \\
Q_{\mathrm{h}} & =n\left[S T_{\mathrm{h}} I-0.5\left(I^{2} R\right)+K\left(T_{\mathrm{h}}-T_{\mathrm{c}}\right)\right],
\end{aligned}
$$

where $n$ is the P-N thermocouple amount, $I$ is the current, $R$ is the $\mathrm{P}-\mathrm{N}$ resistance, and $K$ is the thermal conductance.

TEC coefficient of performance (COP) is given by

$$
\mathrm{TEC}_{\mathrm{COP}}=\frac{\text { Thermal cooling power }}{\text { Electrical input power }} \text {. }
$$

\section{Thermoelectricity Case Studies of Interest}

In the following sections, eighteen assorted thermoelectricity applicable case studies are examined to determine several factors that can be applied and developed to devise a novel CCHP system. The eighteen thermoelectricity case studies analysed are those vital to the research.

2.1. Thermoelectric Device as a Construct, TEG, and TEC. Examined in $[3,4]$, thermoelectric (TE) materials are solidstate energy converters whose combination of thermal, electrical, and semiconducting properties allow them to be used easily to convert waste heat into electricity or electrical power directly into cooling and heating. The materials must be a very good electrical conductor but poor thermal conductors; otherwise, the temperature difference that must be maintained between the hot and cold sides will produce a large heat backflow. A TEG dimensionless figure of merit ZT expresses the efficiency of the P-type and $\mathrm{N}$-type materials that make up a TEG/TEC device at absolute temperature in Kelvin $(273.15 \mathrm{~K})$. The TEG figure of merit $Z$ in per Kelvin is the square of the Seebeck voltage per unit of temperature, multiplied by the electrical conductivity and divided by the thermal conductivity, where $T$ is the absolute temperature. In today's best commercial TEG/TEC devices, $Z T$ is about 1.0; however, various research have shown that $Z T$ can be hugely improved, depending on the classic material treatment approaches, such as nanotechnology, reduce device dimensionality, doping to increase the band structure and using new materials with complex crystalline structure. Thermoelectric materials intensively studied include bismuth and bismuth-antimony, lead telluride and related compounds, silicon-germanium alloys, skutterudites and clathrates, oxides, and some other types: zinc antimonide, half-Heusler compounds, metal silicides, and boron carbide. As stated in [3], there are three categories of TEGs: (i) low temperature $\left(<200^{\circ} \mathrm{C}\right)$, (ii) medium temperature (200$600^{\circ} \mathrm{C}$ ), and (iii) high temperature $\left(600-1000^{\circ} \mathrm{C}\right)$. More 
efficient thermodynamic cycles and designs that reduce material costs are transcending into commercial production. Figure 1 depicts a thermoelectric device as (a) a construct, (b) a TEG, and (c) a TEC.

\subsection{Harness Thermal Energy Using TEGs in a HT-PEM FC} Power System. Researched by [3], TE devices can be used to enhance the efficiency and the load following capability of a high-temperature polymer electrolyte membrane fuel cell (HT-PEM FC). A heat recovery subsystem based on compact plate-fin heat exchangers and TEGs was designed to harvest the system hot exhaust gas for electricity. The maximum power point tracking (MPPT) power conditioning method was also systematically examined. TEGs were integrated into the methanol evaporator of the HT-PEM FC system to improve the entire system load following capability. By reducing heat loss, the system power efficiency can be boosted. The TEG module working modes were various and unique; as a result, they were redefined as thermoelectric heat flux regulators (TERs). Three crucial parameters were determined and they are (i) heat exchanger surface type, (ii) its housing dimensions, and (iii) TEG power conditioning. In light of this, a practical TEG system was recommended to have four subsystems as follows: (i) heat exchanger support structure, (ii) TEG array (converts heat to voltage), (iii) cooling, and (iv) electrical power converters to provide working DC and/or AC voltages to the loads. Figure 2 depicts the researched scheme.

2.3. TEG and Fuel Cell Cogeneration. Studied in [2], an electrical energy conversion efficiency of approximately 15 percent would be required to obtain an acceptable return on investment for thermoelectric devices. As a result, a feasibility study was performed to determine how, assuming $16 \%$ efficiency, thermoelectric devices could impact the US Department of Defence (DoD) power generation capabilities. Based on research indicating energy conversion efficiencies of $20 \%$, thermoelectric devices were built and tested. Of the 27 thermoelectric devices supplied, only 8 were functional; of which, each device produced only $1 \mathrm{~W}$ of electrical power. Current manufacturing processes and design parameters were examined and recommendations made. In concluding the research, more than 40 specific applications (facility and nonfacility) for thermoelectric devices were investigated, in which, it was realised that in all these applications, thermoelectric devices form factor which is crucial, enabled TEGs to be mounted on hot surfaces, in hot gas streams, along processes to absorb radiant heat, or integrated in stacks or process insulation. This adaptability allows thermoelectric systems to be integrated within industrial processes with minimal impacts on the process. In Table 1, it is shown that thermoelectric devices have the potential to increase efficiency and when used with different types of fuel cells, their respective power generations were increased by $\sim 7$ to $10 \%$. Furthermore, as shown in Table 2, TE devices generated $464000 \mathrm{MWh}$ of electricity each year when applied to lowgrade heat $(\mathrm{LGH})$ generated from military processes, which translates yearly to greater than $\$ 34.5$ million cost avoidance for the production of electricity and results in approximately
1.5 billion BTUs of energy production from normally discarded LGH. Additionally, this equates to 268000 barrels of oil yearly equivalent.

2.4. Ionic Thermoelectric Supercapacitor (ITESC). As stated in [5], temperature gradients are generated by the sun and a vast array of technologies, which can induce molecular concentration gradients in solutions via thermodiffusion (Soret effect). In the case of ions, this leads to a thermovoltage that is determined by the thermal gradient $\Delta T$ across the electrolyte, together with the ionic Seebeck coefficient $\left(\alpha_{i}\right)$. Due to a lack of strategy to harness the energy from the Soret effect, redox-free electrolytes have not been explored in thermoelectric applications. As a result, a new means to harvest energy from intermittent heat sources and converted into stored charge via the ionic Soret effect in an ionic thermoelectric supercapacitor (ITESC) was demonstrated-from which it was shown that the stored electrical energy of the ITESC is proportional to $\left(\Delta T \alpha_{i}\right)^{2}$ and that its $\alpha_{i}$ reaches beyond $10 \mathrm{mV} / \mathrm{K}$. The resulting ITESC can convert and store several thousand times more energy as compared to a conventional TEG connected in series with a supercapacitor. According to [5], it was demonstrated for the first time that the Soret effect in a polymer electrolyte leads to a significant ionic thermoelectric effect that could be used to charge a supercapacitor. The presented ITESC device requires a variation in the applied temperature gradient to function, which makes the concept suitable for intermittent heat sources, such as the sun. They explained potential enhancements of the ITESC concept and forecasted the heat-to-electricity charging conversion efficiency to be able to improve if good thermoelectric electrolytes are designed with low specific heat capacitance, low thermal conductivity, large Seebeck coefficient, and high ionic conductivity. Importantly, all materials (polymer and inorganic salts) consisting of the ITESC are fully compatible with industry processing. Contrary to a usual thermoelectric device constituting a semiconductor and two metal contacts, where a constant electrical power can be provided to an external load by imposing a temperature gradient along the metal-semiconductor-metal stack, the same harnessing principle is not directly applicable if the semiconductor is replaced by an electrolyte solution with ions as charge carriers. The reason for this is that the thermodiffused ions are stopped at the surface of the metal electrode and cannot pass through the external circuit. Furthermore, akin to classic electronic materials, the efficiency will increase with higher ionic conductivity, higher Seebeck coefficient and lower thermal conductivity. However, for materials with the same $z T$ value, the maximum efficiency from typical TEGs is greater than from ITESC. This is because the output power is not constant in ITESC, which instead decreases with time as illustrated in Figure 3(a). Figure 3(b) summarily explains the research on ITESC.

2.5. Small Modular TEG Power Generation Analysis. According to [6], from the thermoelectric characterisation, it can be concluded that to generate more voltage, TEGs must be connected in series and in parallel to generate more current. Furthermore, the voltage and current (power) increases 


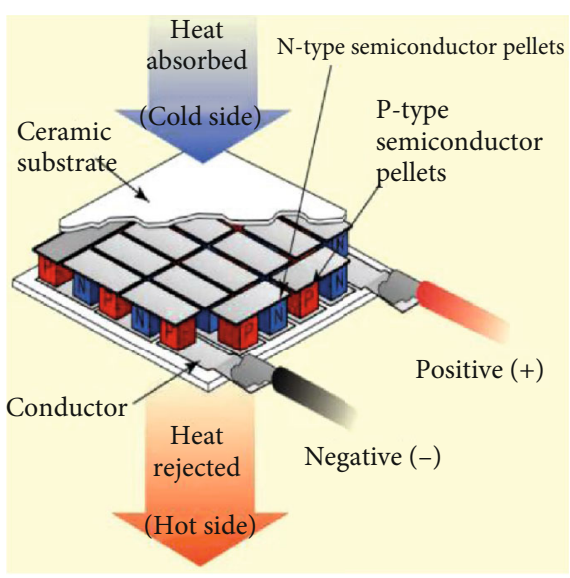

(a)

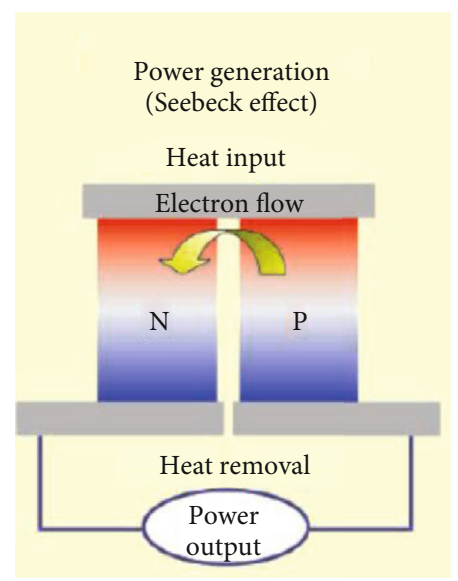

(b)

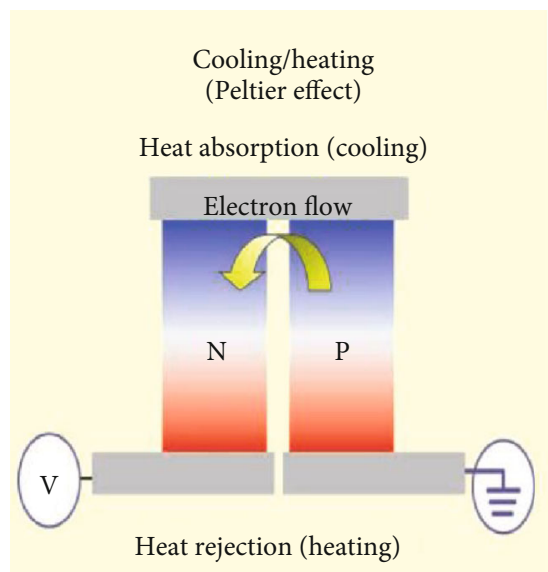

(c)

FIgURE 1: Thermoelectric device as (a) construct, (b) TEG, and (c) TEC (adapted from [4]).

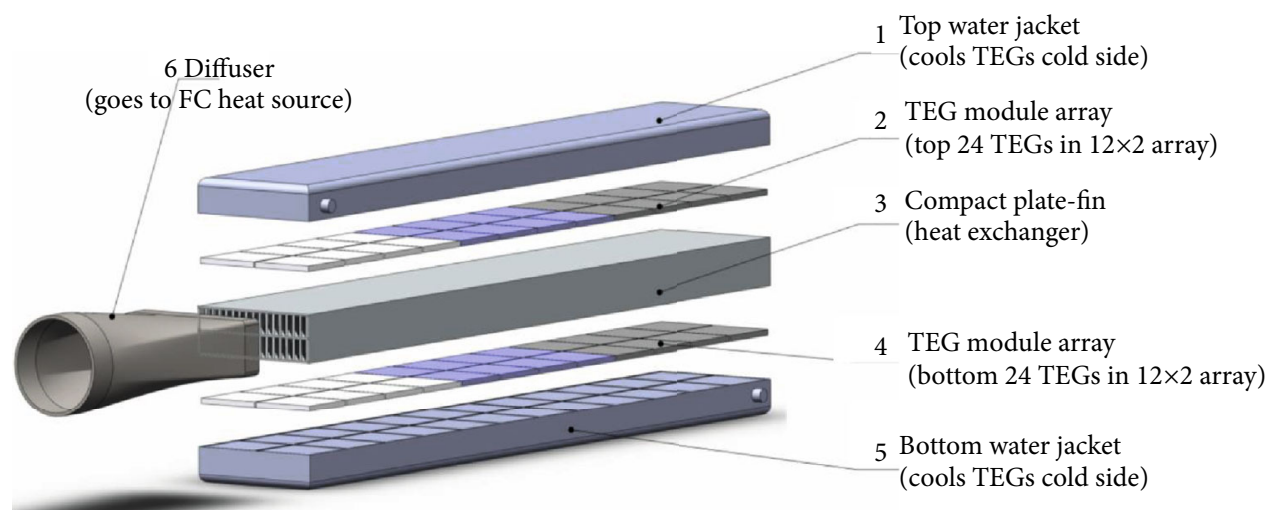

FIgURE 2: TEG and HT-PEM FC energy harvesting setup (adapted from [3]).

TABLE 1: Efficiency improvement of fuel cells incorporating thermoelectric devices (adapted from [2]).

\begin{tabular}{|c|c|c|c|c|c|c|}
\hline Fuel cell type & $\begin{array}{l}\text { Operating } \\
\text { temperature }\end{array}$ & Efficiency & $\begin{array}{l}\text { Heat percentage } \\
\text { waste }\end{array}$ & $\begin{array}{c}\text { Power generation } \\
\text { increase }\end{array}$ & $\begin{array}{l}\text { Final } \\
\text { efficiency }\end{array}$ & $\begin{array}{c}\text { Efficiency } \\
\text { improvement }\end{array}$ \\
\hline LT-HT PEM FC & $80-180^{\circ} \mathrm{C}$ & $40 \%$ & $60 \%$ & $9.6 \%$ & $49.6 \%$ & $24 \%$ \\
\hline Alkaline FC & $65-220^{\circ} \mathrm{C}$ & $60 \%$ & $40 \%$ & $6.4 \%$ & $66.4 \%$ & $11 \%$ \\
\hline $\begin{array}{l}\text { Phosphoric acid } \\
\text { FC }\end{array}$ & $205^{\circ} \mathrm{C}$ & $37-42 \%$ & $60 \%$ & $9.6 \%$ & $49.6 \%$ & $24 \%$ \\
\hline $\begin{array}{l}\text { Molten carbonate } \\
\text { FC }\end{array}$ & $650^{\circ} \mathrm{C}$ & $45 \%$ & $55 \%$ & $8.8 \%$ & $53.8 \%$ & $20 \%$ \\
\hline Solid oxide FC & $600-1000^{\circ} \mathrm{C}$ & $45-65 \%$ & $45 \%$ & $7.2 \%$ & $62.2 \%$ & $13 \%$ \\
\hline
\end{tabular}

Table 2: Potential annual benefits of thermoelectric device application (adapted from [2]).

\begin{tabular}{lccccc}
\hline Sector & $\begin{array}{c}\text { Electricity } \\
\text { generation } \\
(\mathrm{MWh})\end{array}$ & $\begin{array}{c}\text { Generation } \\
\text { capacity } \\
(\mathrm{MWe})\end{array}$ & $\begin{array}{c}\text { Cost } \\
\text { avoidance } \\
(\$ 1 \mathrm{M})\end{array}$ & $\begin{array}{c}\text { Oil equivalent saved } \\
\text { (thousands of barrels) }\end{array}$ & $\begin{array}{c}\text { Carbon emissions } \\
\text { savings (metric } \\
\text { kilotons) }\end{array}$ \\
\hline $\begin{array}{l}\text { Defense } \\
\begin{array}{l}\text { Utility/nonutility } \\
\text { generation (CTC \& LTI }\end{array}\end{array}$ & 464000 & 53 & 34.5 & 268 & $\begin{array}{c}\text { Number of } \\
\text { potential } \\
\text { applications }\end{array}$ \\
$\begin{array}{l}\text { 2001b) } \\
\begin{array}{l}\text { US industries of the } \\
\text { future (CTC \& LTI 2001a) }\end{array}\end{array}$ & 603000000 & 68000 & 45000 & 355000 & 43 \\
\hline
\end{tabular}




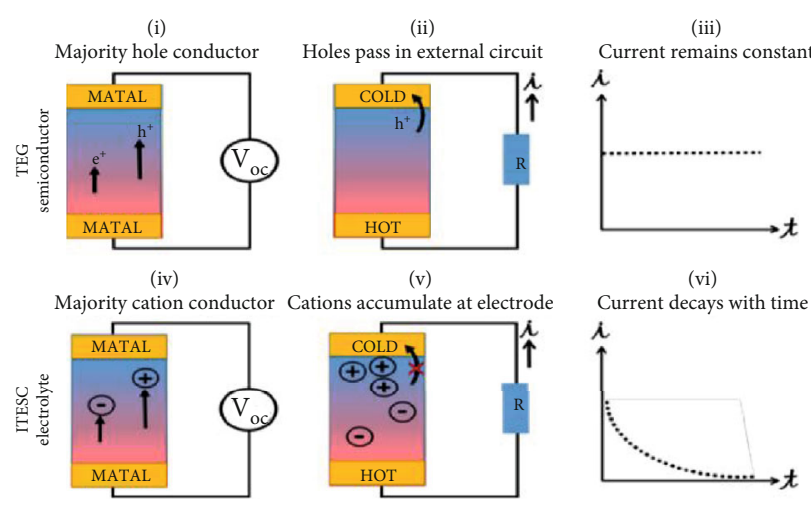

(a) TEG and ITESC power generation principles comparison

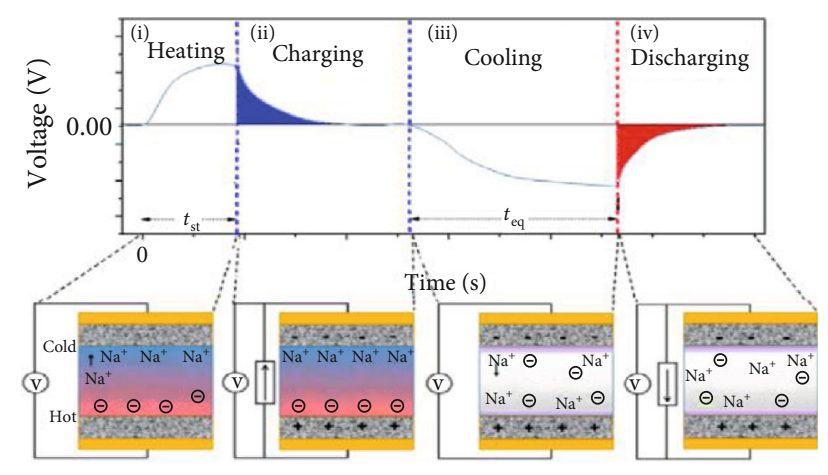

(b) ITESC operation principle

FIGURE 3: Ionic thermoelectric supercapacitor summary (adapted from [5]).

when the TEG cold side is cooled-which was studied with a setup with and without a fan. Figures 4(a)-4(d) summarise the experiments. NB: TE device P-N thermocouples are inherently connected electrically in series and thermally in parallel [40]. The reason is to increase electrical conductivity and decrease thermal conductivity.

\subsection{TEG and Microturbine Combined Heat and Power (CHP)} System. In [7], a thermodynamic model was developed for the TEG and microturbine combined power generation system as shown in Figure 5. The numerical results showed that the addition of the TE device can almost double the CHP output power generated. Also in an investigation in [2], TEG cogenerations are more efficient compared to other equivalent forms of CHP systems.

\subsection{High-Temperature TEG Module Characterisation System.} Stated in [8], thermoelectric (TE) power generators (TEGs) are used to convert thermal energy directly into electrical energy; however, present TEGs have limited conversion efficiencies and lack the capacity to penetrate these highly important industry sectors, though successfully applied in niche fields, such as space applications, scientific equipment facilities, and hot lasers. Most of research efforts concentrated on the development of novel TE materials, which would have higher $z T$-a value that signifies how good/bad a thermoelectric material is. It is a widely established fact that for practical considerations the $z T$ for any given thermoelectric material, P-type or N-type, has to exceed unity. However, knowing the basic characteristics of a given thermoelectric material cannot be directly related to the conversion efficiency of a TEG. The manufacturing of a TEG includes selection of TE materials, electrodes, insulating plates, adhesives, and module architecture. The complexity of this task is evident by the few number of research papers describing the characterisation of thermoelectric modules. Furthermore, as claimed in [8], in contrast to existing TE material characterisation systems, there are no commercial systems available that would allow accurate characterisation of fabricated TEGs. Hence, their research was undertaken to design and construct a comprehensive computer-controlled characterisation system, which would allow efficient characterisation of in-house built TEG modules. This system incorporated all of the abovementioned features in a bench-top engineering solution integrating high power heating, liquid cooling, hydraulic compression, force, and temperature sensing-all in a controllable atmosphere. The measurement system has been specifically designed to accommodate a wide range of TEG modules suited for low- to high-temperature applications. The system accurately reproduced application conditions the TEG devices may be subjected to in a real world environment, which was tested with direct heat flux measurements using reference materials. Bismuth telluride-based Thermonamic TEHP-12656-0.3 and Everredtronics TEG 127-50D TEG modules were characterised. Their performance data were analysed and compared to the available manufacturer data. The measured data correlated with anticipated values, though some discrepancies were noticed due to overlooked inaccuracies in the traditional module resistance measurements. Figures 6(a)-6(c) show some results of the study.

2.8. On-Chip TEC and TEG Model-Based Design. As in [20], TE devices for the last decades have been used in many power generation or cooling applications; such as energy recovery in space and cooling of sensors located in heat-sinking missiles. This research focused on the possibility of embedding thermoelectric devices within electronic packaging for both hotspot TEC and TEG. The commercial CFD solver FLUENT and the analog electronic circuit simulator SPICE were used to study operations of single and arrayed TECs and TEGs integrated inside a FLUENT model-based chip-which were arranged in a programmable $3 \times 3$ array to be up to 9 TECs and/or TEGs depending on the test configurations.

This array of nine TECs or TEGs, as depicted in Figures $7(\mathrm{a})$ and $7(\mathrm{~b})$, provided vital results related to thermal coupling of adjacent TECs and transient pulse operation of TECs. Figure 7 (c) shows the cooling currents and their effects to the TEC (at mid hotspot of 5 as shown in Figure $7(\mathrm{~b})$ ) at various levels (from the steady state of $3 \mathrm{~A}$ to transient levels of 6,8 , and $10 \mathrm{~A}$. Figure 7 (d) illustrates the cooling coupling among TECs, which is strongest when more TECs are turned ON and the cooling is also best in a steady state whereas weakest with less TECs turned ON as 


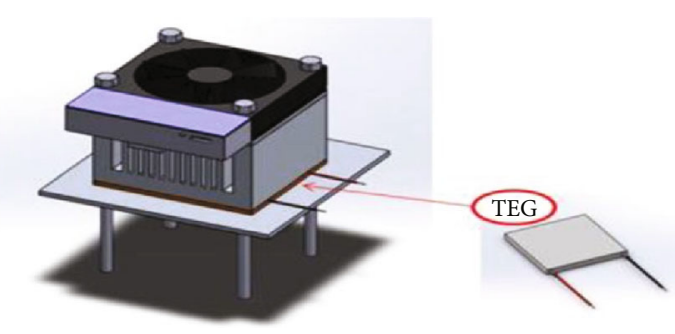

(a) Model of setup

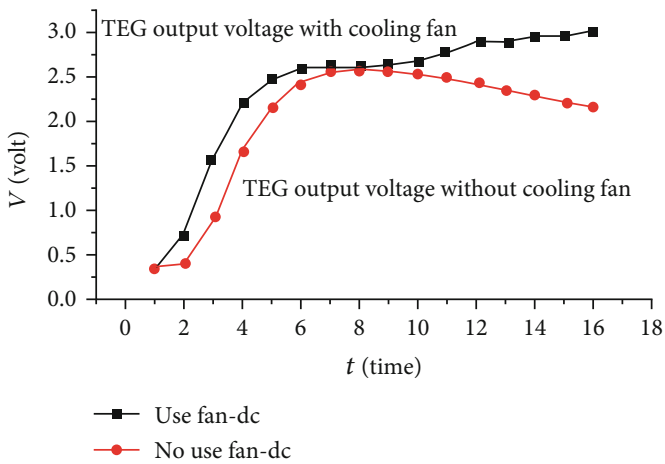

(c)

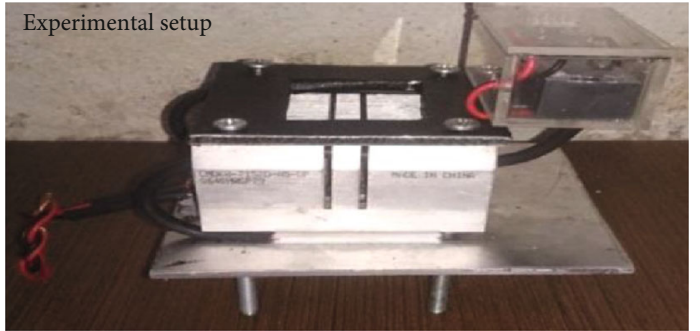

(b) Experimental setup

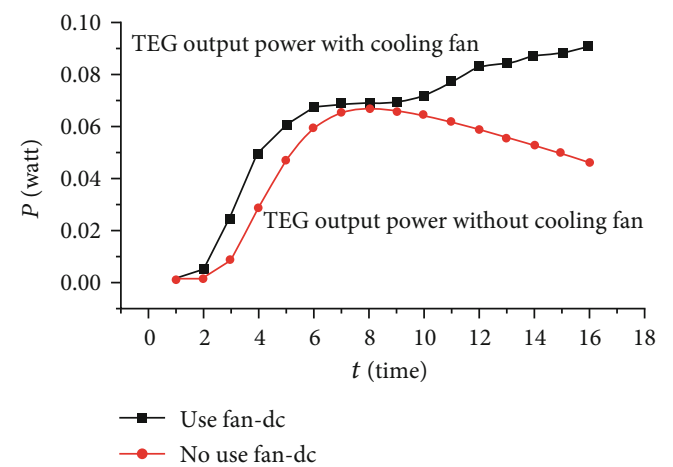

(d)

FIgURE 4: Modular TEG characterisation (adapted from [6]).

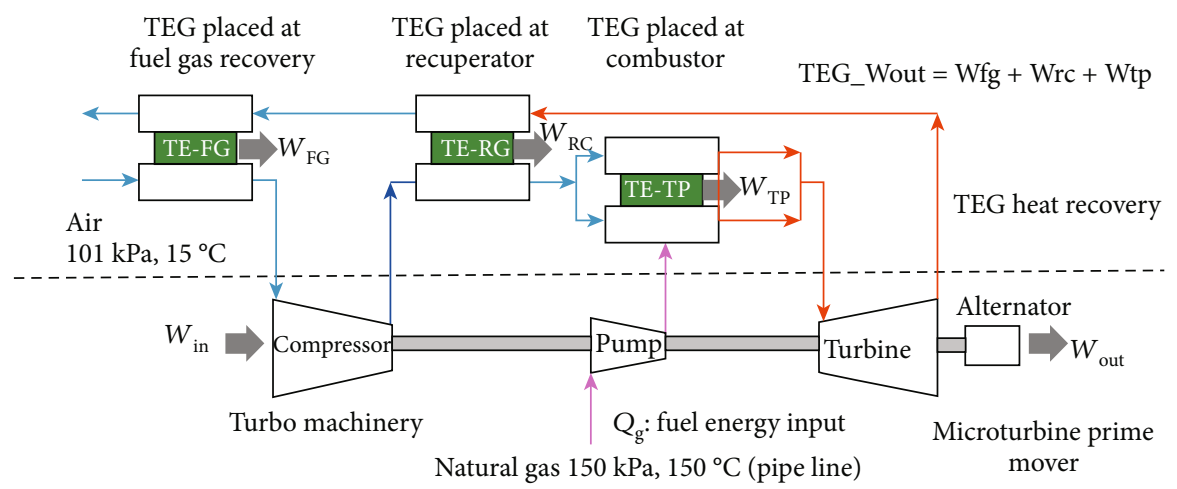

FIGURE 5: TEG and microturbine cogeneration (adapted from [7]).

well as worst in transient conditions (i.e., a large current is involved). From the analyses of various pulse shapes portrayed in Figure $7(\mathrm{e})$, the square root pulse shown in Figure $7(\mathrm{f})$ was noticed to yield the best cooling considering all the important parameters-maximum cooling, temperature overshoot after current pulse is turned off, total energy used, and settling time. As per Figure 7(g), it was also established that the shortest duration of the transient pulse positively affects the cooling, which degrades if left longer, as the longer the pulse switch ON current, the more Ohmic heating-as evident in the initial control results for random hotspots using the square root pulse. For all, frequent hotspots should be cooled with steady-state currents and infrequent hotspots may be cooled using square root transient pulses of least period. A thinner TIM and/or bigger thermal conductivity enhances the cooling.
Similar analyses of the on-chip TEGs yielded vital and intuitive results. As shown in Figure 8(a), the maximum power transfer (MPT) occurred at a load resistance bigger than the TEG device resistance, contrary to the established fact that MPT occurs when load and source resistances are equal. This deviation was mainly due to the dependence of the generated power on the temperature difference between the hot and cold junctions. This temperature difference is also dependent on the generated current and is inversely proportional to the load resistance. Hence, as depicted in Figure 8(b), useful MPT occurs only when the load and TEGs resistances are (i) equal and (ii) the TEG temperature is constant. Also increasing the background heat flux initially increased useful power (load power) linearly which later changed to a parabolic increment, as power $=I^{2} R$. Figure $8(\mathrm{c})$ also showed that reducing the TIM thickness between the hot 


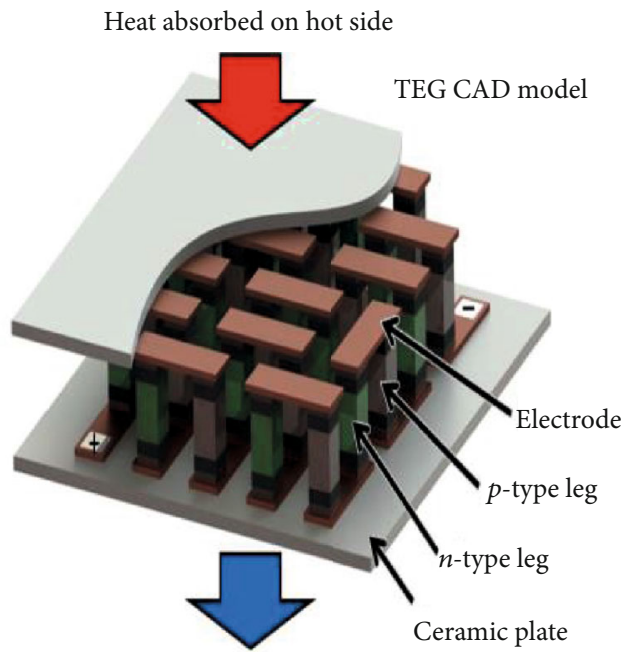

Heat rejected on cold side

(a)

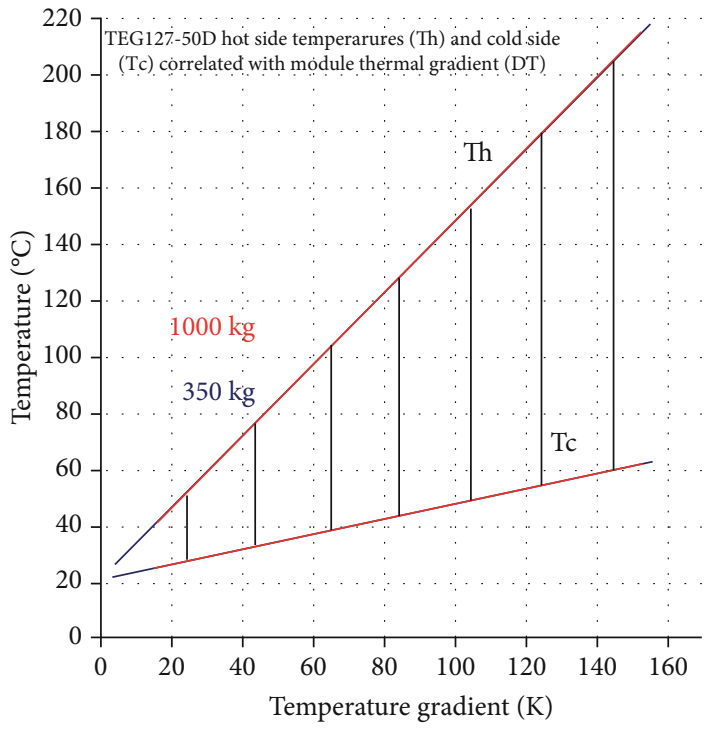

(b)

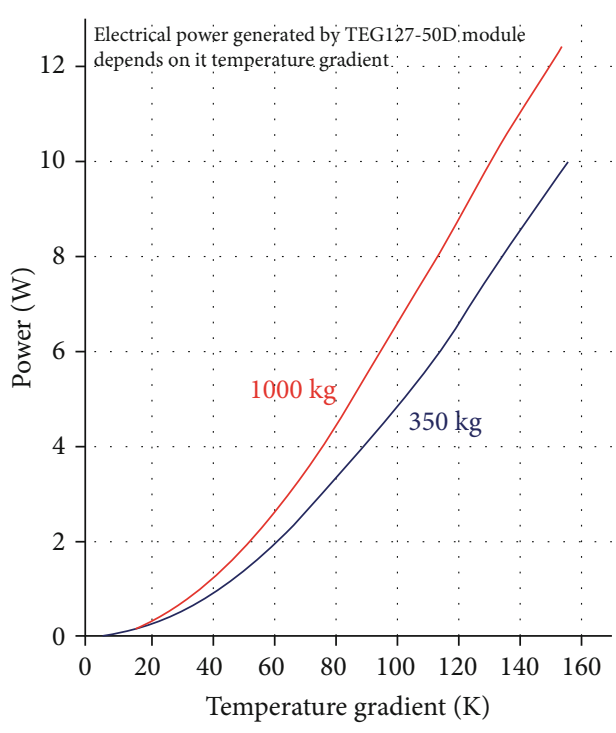

(c)

FIGURE 6: High-temperature TEG characterisation (adapted from [8]).

junction of the TEG and the surface of the chip yielded improved power generation from the TEGs. The effect of transient to on-chip TEG is trivial, since a TEG is passive and there is a dynamic change in on-chip heat flux. Finally, the result in Figure 8(d) displayed a study done on various TEG arrays (see Figure 7(b) for layout), to research the total useful power and average useful power per TEG in $\mathrm{mW}$ for five setups with varying numbers of on-chip TEGs as follows: (i) TEG 5 only; (ii) TEGs 3, 5, and 7; (iii) TEGs 1, 3, 5, 7 and 9; (iv) all TEGs except 2 and 8; and (v) all TEGs 1-9. It was established that adding more on-chip TEGs always first increases the total useful power generated; however, on-chip TEG efficiency decays when more are added due to overcrowding.

2.9. Hybrid TEC-TEG Modelling and Experimentation. According to [10], a new thermoelectric cooler-thermoelectric generator (TEC-TEG) module was simulated (Figure 9(c)) and experimentally (Figures 9(d)-9(e)) studied using COMSOL multiphysics modelling software as illustrated in Figures $9(\mathrm{a})-9(\mathrm{~g})$. The researched module consisted of a TEC (Figure 9(a)), TEG (Figure 9(b)), and total system heat-sink Figures 9(c)-9(e) all connected thermally in series. An input voltage ( 1 to $5 \mathrm{~V}$ ) was applied to the TEC where the electrons by means of the Peltier effect converted heat from the upper side of the module ( $\left.T_{\text {cold TEC }}\right)$ to the lower side ( $T_{\text {hot TEC-TEG }}$ ) creating temperature difference. The TEG acts as an intermediate heat-sink for the TEC by transferring this waste heat to the total system heat-sink and converting an amount of this heat into electricity by a phenomenon called the Seebeck effect. The temperature contour of TEC-TEG and TEG's electric potential at different TEC input voltage: (i) $V=0$ and $V=1$, (ii) $V=2$ and $V=3$, AND (iii) $V=4$ and $V=5$ were measured. Figure $9(\mathrm{f})$ shows the effect of the input voltage of TEC on the temperature difference $(\Delta T)$ 


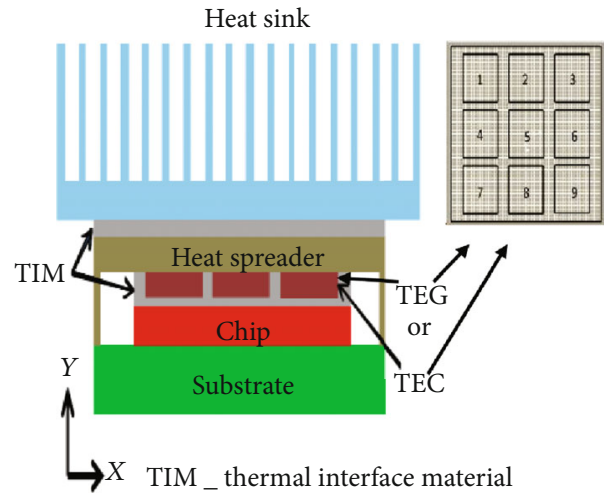

(a)

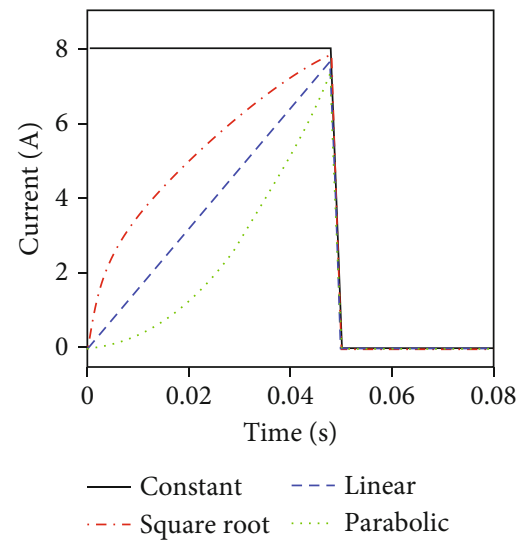

(e)
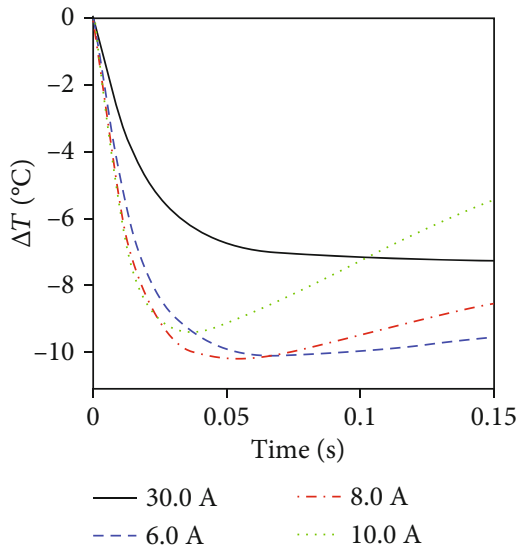

(c)

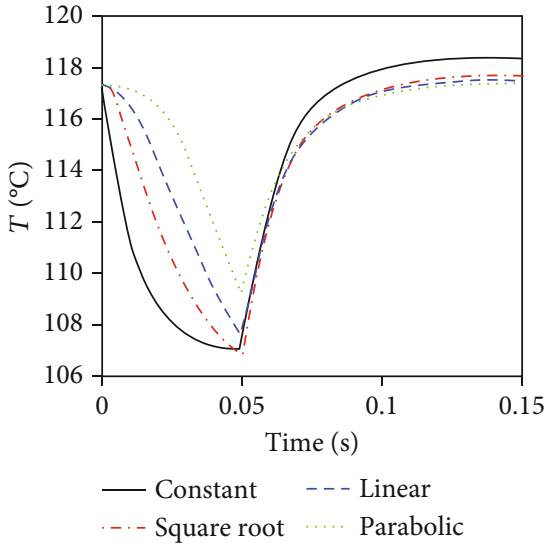

(f)
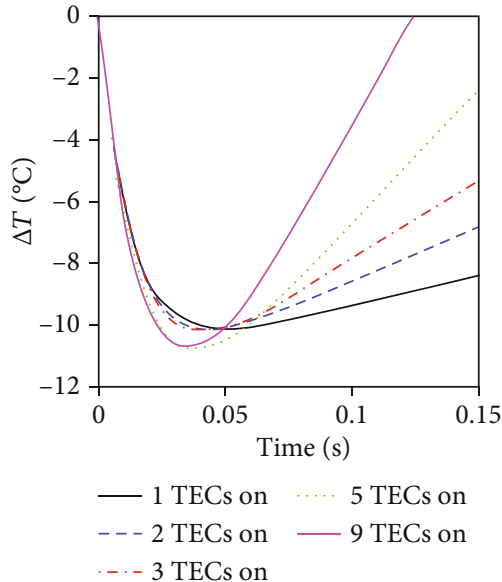

(d)

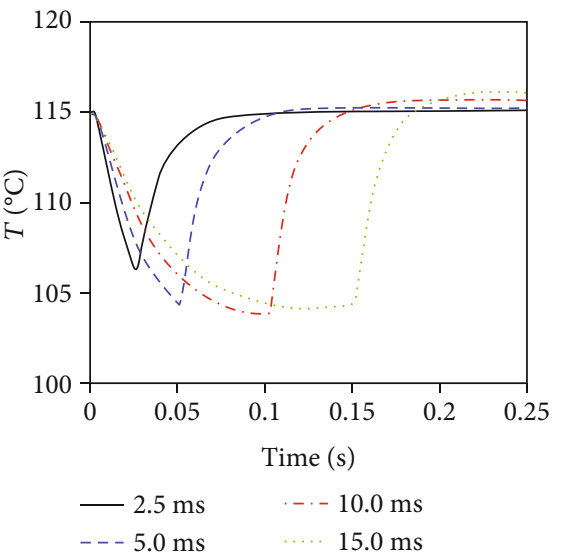

(g)

Figure 7: Simulation summary of the modelled on-chip TEC (adapted from [20]).

across the cold and hot sides of TEG in both simulated and experimented results-where $\Delta T$ is directly proportional to the input voltages, as well as directly proportional to the TEG output voltages as shown in Figure 9(g) correlated results.

2.10. Nonstationary TEGs. In $[12,21,22]$, a review of theoretical publications on nonsteady thermoelectrics are presented, in which different aspects of nonstationary and pulsed processes in thermoelectric materials and devices were examined. Theoretical analyses of the dynamic behaviour of thermoelectric devices, including analyses of small and large signals of thermoelectric generator, are given and details of the principle of quasi-equilibrium thermoelectricity are discussed as well. Special attention was given to the theoretical study of the nonroutine regime of nonsteady thermoelectricity-fasttime dependence of thermoelectric properties when TE material/device is well out of equilibrium. Theoretical results of fast-time dependence gave reason to think that it can increase the output electrical power of thermoelectric generator compared to stationary techniques of operations.

Experimental results acquired using first ever nonstationary thermoelectric generator prototype, which was designed for operation in fast-time dependence mode, was disclosed. There are ongoing R\&Ds to confirm that more electrical output power can be obtained in the AC mode
(AC frequency about hundreds of $\mathrm{kHz}$ ) than in DC mode, and TE parameters of interests include energy capacity, speed of response, response time improvement, temperature dependence of physical parameters, and output characteristics; accounting for the Peltier heat production, effectiveness of side surfaces of thermal insulation, and thermal stabilisation based on the model of finite length. In the early 90s, Aspen and Strachan filed a priority patent on thermoelectric energy conversion in high-frequency mode and later published results of development and demonstration tests of $\mathrm{MHz}$ thermoelectric generator, which became the first work on thermoelectric operating far from equilibrium. Strachan, who developed a vibrator with it to break kidney stones also noticed that his device could function as a heat pump (to produce ice) or with temperature difference between both sides, it could generate electrical power sufficient to operate a small fan. Jon Schroeder in 1994 announced a ring-shaped TEG pulsed at $60 \mathrm{~Hz}$ and he published a paper about it in 1999 and built a prototype in 2004 but regrettably, it did not work.

Schroeder further designed a ring-shaped TE device called the Schroeder ring. In which, heat is produced in the centre by hot gases, which can be combustion gases from natural gas. The heat is transferred by convection and radiation to the radial blades. Nonstationary TEGs are TEGs with high values of capacitance in the Farad range (akin to 

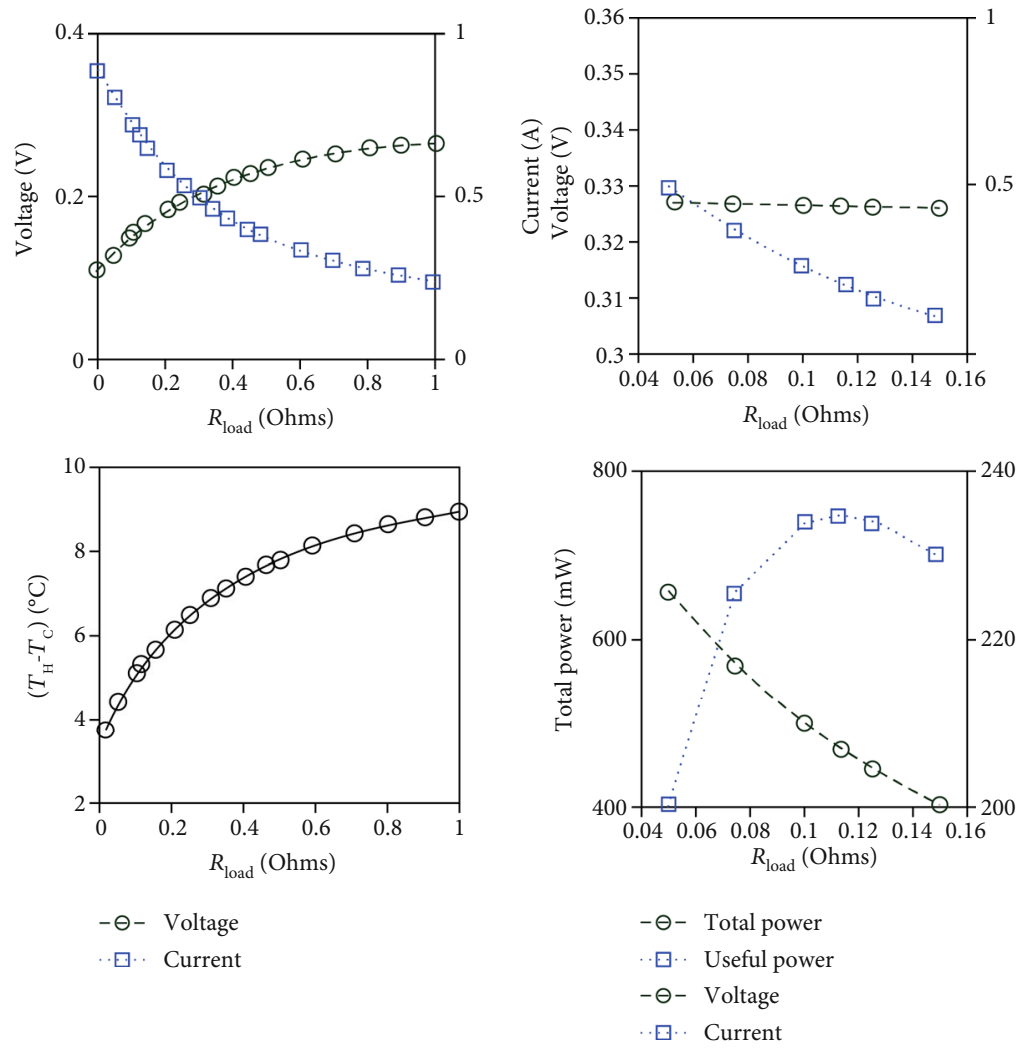

(a)

(b)
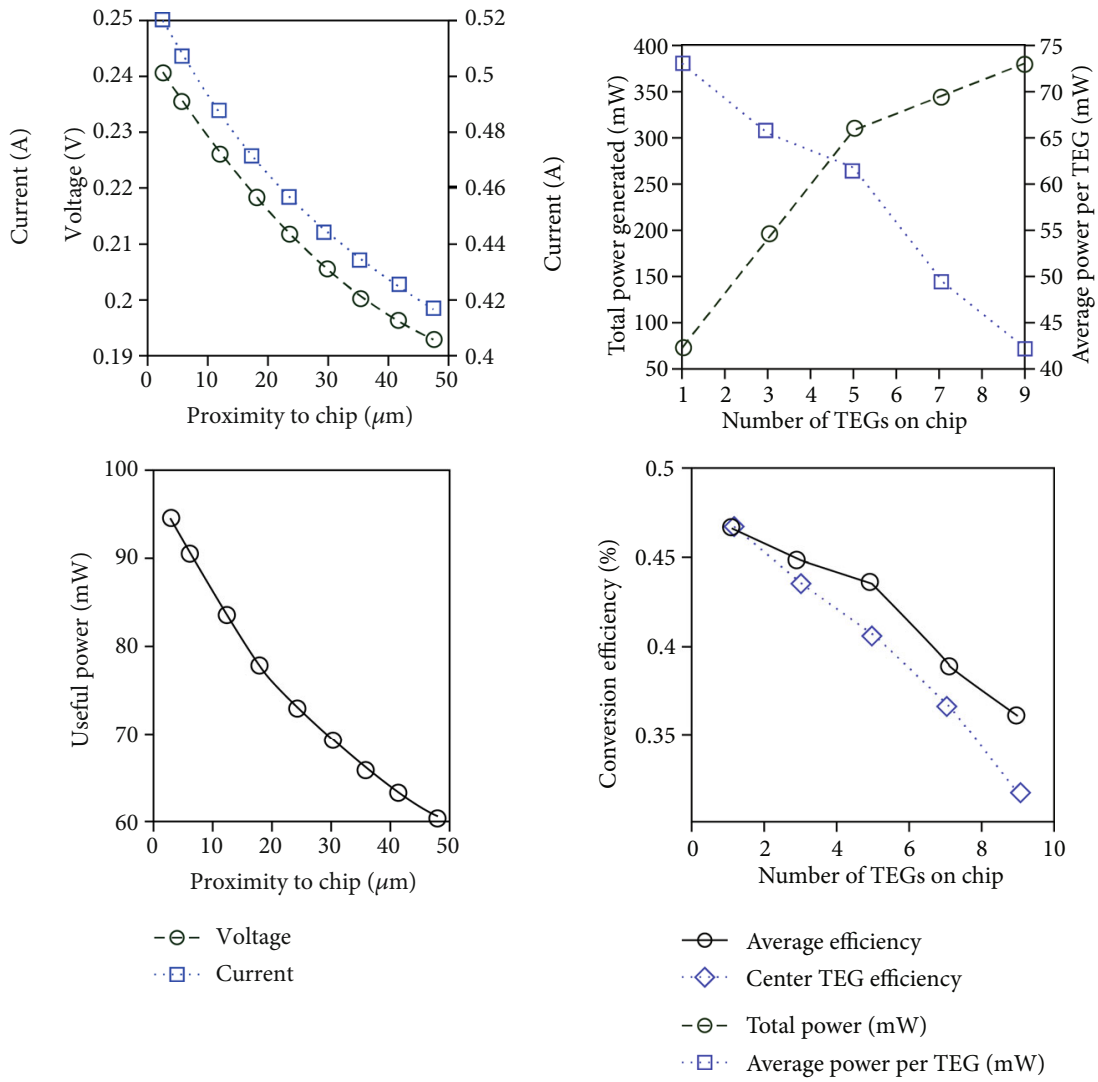

(c)

(d)

Figure 8: Simulation summary of the modelled on-chip TEG (adapted from [20]). 


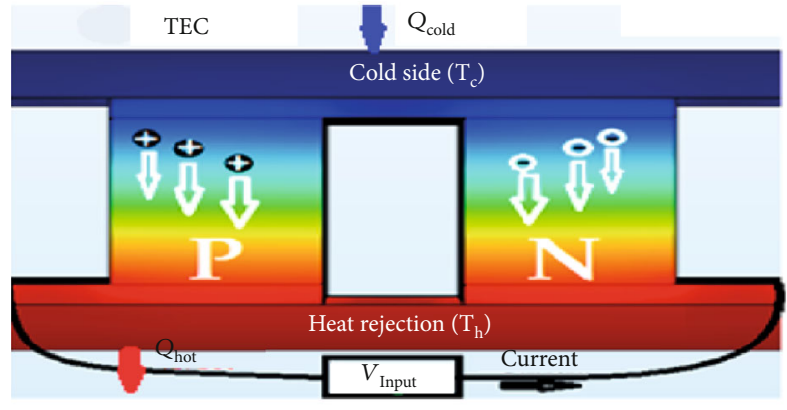

(a)

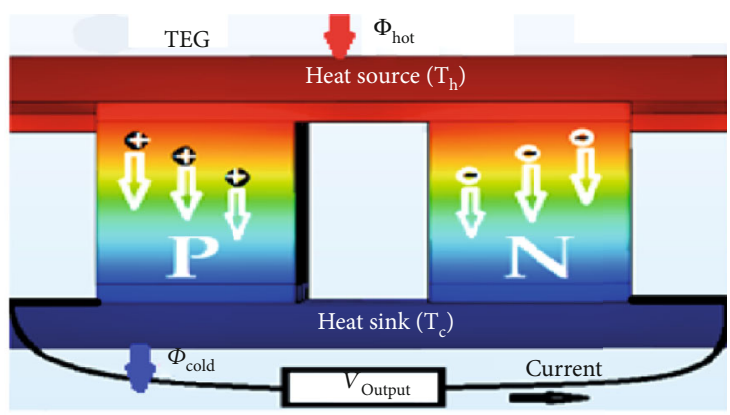

(b)

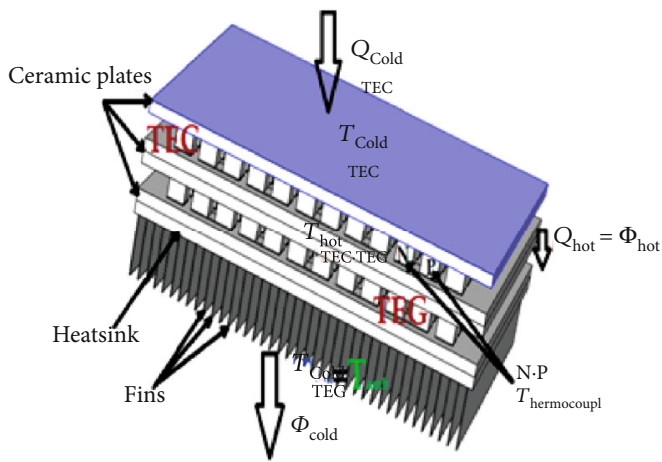

(c)

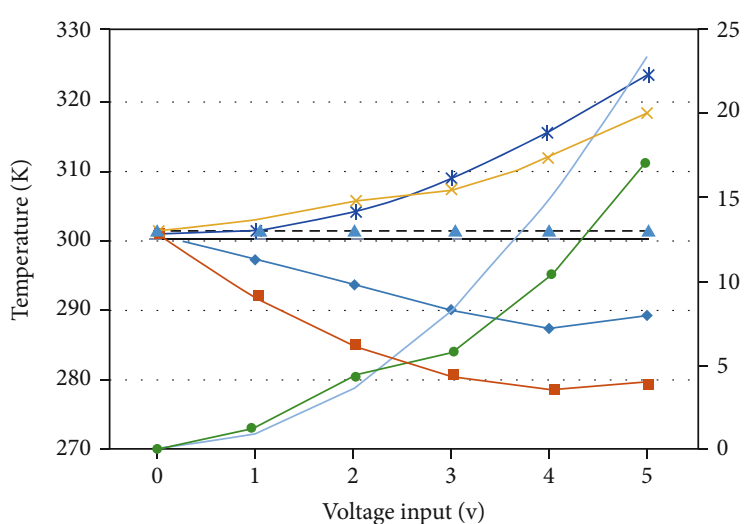

$$
\begin{array}{ll}
\rightarrow \text { Experiment TECc } & * \text { Simulation TEC-TEG } \\
\rightarrow-\text { Simulation TECc } & -T \text { amb } \\
-\sim-T \text { Heatsink } & \rightarrow \Delta T \text { (TEG) Exp } \\
\rightarrow \text { Experiment TEC- } & -\Delta T \text { (TEG) Sim }
\end{array}
$$

(f)

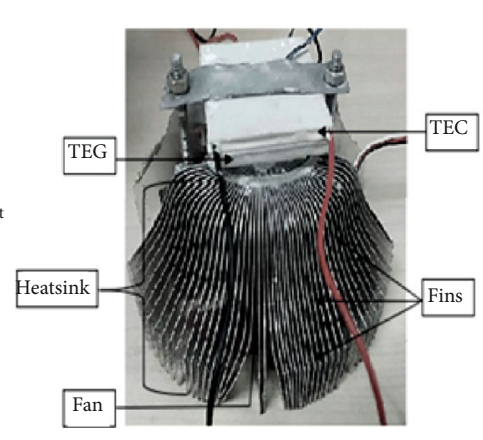

(d)

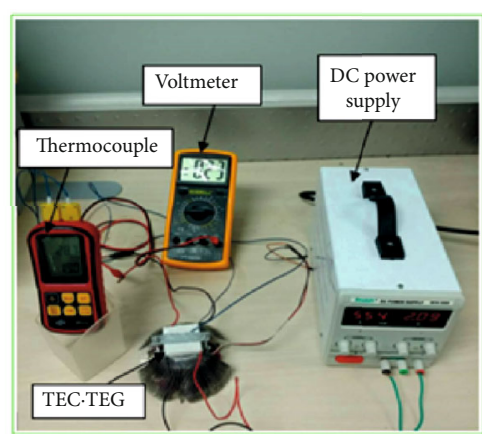

(e)

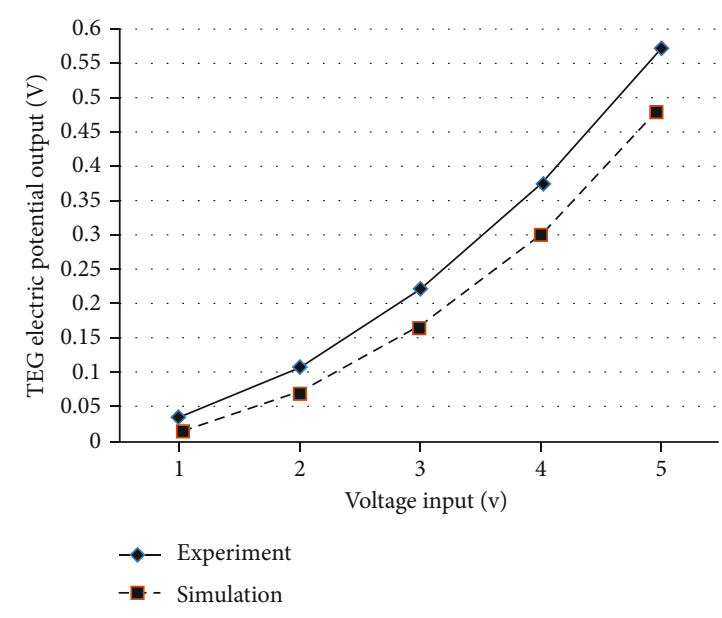

(g)

FIGURE 9: Summary of the simulated model and experimented TEC-TEG (adapted from [10]).

supercapacitors), which makes them pulse operable at more than $100 \mathrm{kHz}$. Apostol postulated that pulsing can improve TEG efficiency due to ultrafast conduction as predicted. Nedelcu and Stockholm observed in 2001 that, when electrical current is pulsed at $50 \mathrm{kHz}$, the electrical power was constant at $R_{\mathrm{s}}>R_{\mathrm{L}}$-this demonstrated that small electrical resistance (impedance to be correct) should be taken into account to extract electrical power efficiently. Nedelcu later confirmed Apostol's work by building a TEG with four commercial TEGs connected electrically in parallel. The electrical current output was pulsed using MOSFETs at around $200 \mathrm{kHz}$. The output current from the transformer is recti- fied. The load was $100 \mathrm{~W}$ filament light bulb. The voltage measured was $210 \mathrm{~V}$ and current $0.4 \mathrm{~A}$ giving an electrical output power of $84 \mathrm{~W}$. The total efficiency (including heat losses) is $8.4 \%$ deduced from the $\sim 1 \mathrm{~kW}$ heat source. This approach has about twice higher conversion efficiency to when operated in DC mode. Figure 10 illustrates how a TEG electrical output power is pulsed.

2.11. TEG Design in Dynamic Thermoelectric (TE) Energy Harvesting. Presented in [9] is an analysis of the TEG design for dynamic TE harvesting - which enables electricity generation from temperature fluctuations in an environment, such 


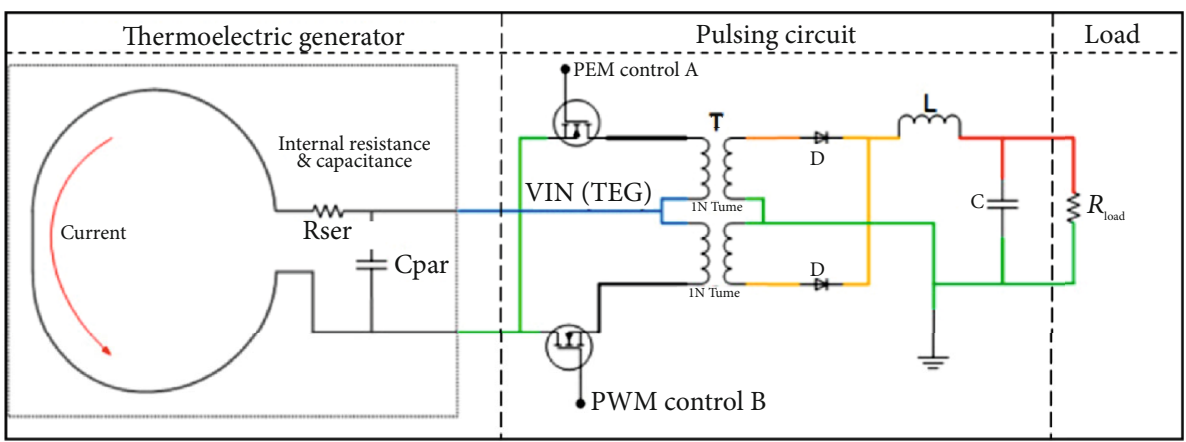

Figure 10: Pulsing TEG electrical output power using MOSFETs (adapted from $[21,22]$ ).

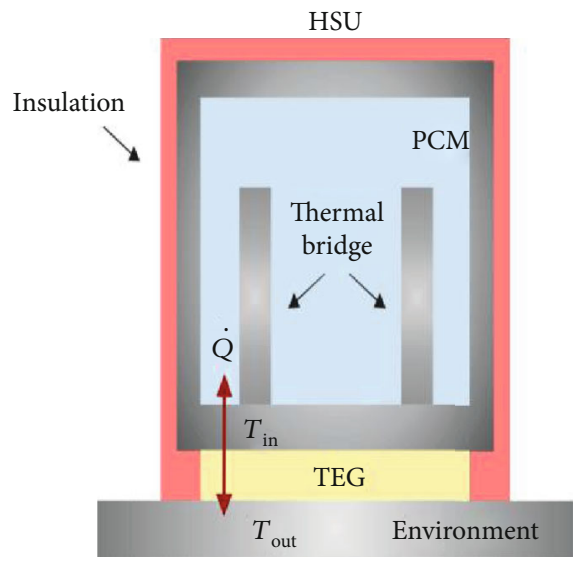

(a)

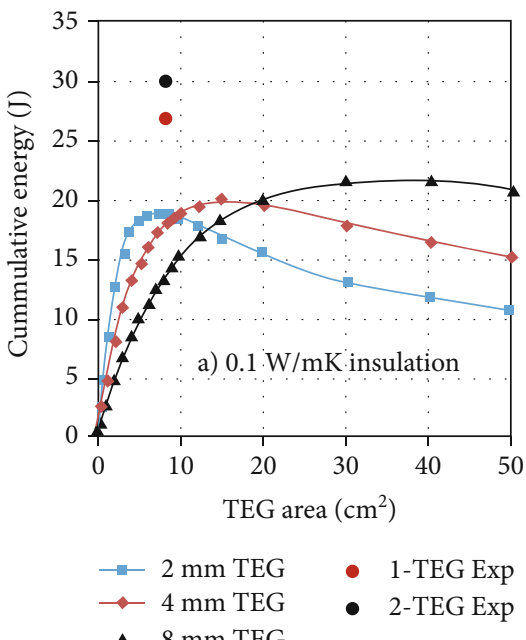

(b)

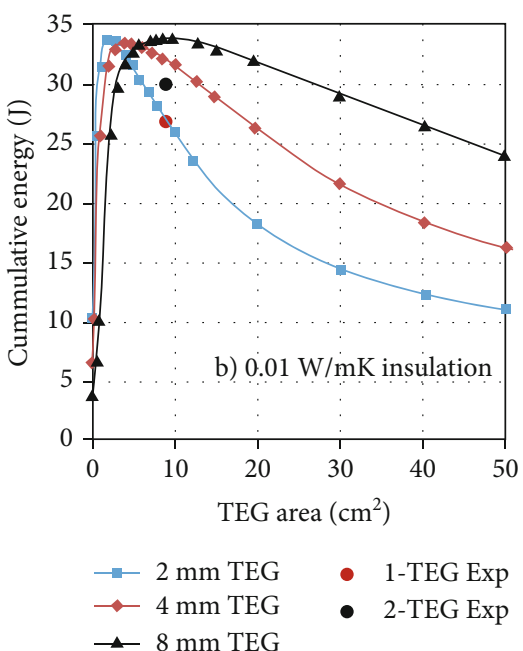

(c)

Figure 11: TEG design in dynamic TE energy harvesting (adapted from [9]).

as a vehicle body or an industrial machine. Shown in Figure 11, it employed a heat storage unit (HSU), with a phase change material (PCM) to increase heat storage, insulated from the environment and in thermal contact with a TEG. This available energy for a given temperature cycle is finite and determined by the HSU capacity. It was demonstrated by simulation and experimentally that specific TEG designs can boost the energy output by optimizing the balance between heat leakage and dynamic response delay. A 3D-printed double wall HSU was developed for the experiments. The output energy of $30 \mathrm{~J}$ from $7.5 \mathrm{~g}$ of phase change material from a temperature cycle between $\pm 22^{\circ} \mathrm{C}$ is shown-which is enough to supply typical duty-cycled wireless sensor platforms. The research showed that total maximum potential performance is achieved with thicker TEGs and choosing a specific surface coverage area. TEGs of various thicknesses were tested and shown in Figure 11. These outcomes may serve as guidelines for the design and fabrication of dynamic TE harvesters for applications requiring surroundings with moderate temperature $\left(<50^{\circ} \mathrm{C}\right)$ variations.

2.12. TEG and $1 \mathrm{~kW}$ Low-Temperature (LT) PEM FC Waste Heat Recovery. In [14], fuel cell is a device that generates elec- tricity through the electrochemical reaction between hydrogen and oxygen. A major by-product of the exothermic reaction is waste heat. The recovery of this waste heat has been subject to research in order to improve the overall energy utilisation. However, nearly all of the investigations focused on high-temperature fuel cells using advanced thermodynamic cycles due to the high quality of waste heat. In this publication, the method, characteristics, and challenges in harvesting waste heat from a low temperature fuel cell using a direct energy conversion device were studied. A heat recovery system for an open cathode $1 \mathrm{~kW}$ LTPEM FC was developed using a single unit of TEG attached to a heat pipe. The power output of the fuel cell was varied to obtain the performance of TEG at different stack temperatures. Natural and forced convection modes of cooling were applied to the TEG cold side. This was to simulate the conditions of a mini fuel cell vehicle at rest and in motion. The experimental results were analysed and a mathematical model based on the thermal circuit analogy was developed and compared. Forced convection mode resulted in higher temperature difference, output voltage, and maximum power which are $3.3^{\circ} \mathrm{C}, 33.5 \mathrm{mV}$, and $113.96 \mathrm{~mW}$, respectively. The heat recovery system for a $1 \mathrm{~kW}$ LT-PEM FC using a single TEG was successfully established and improved the electricity 


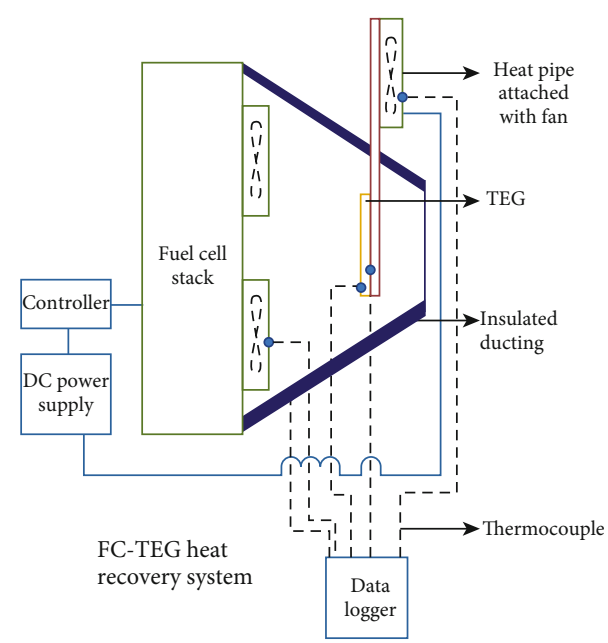

(a)

Experimental setup of TEG-FC

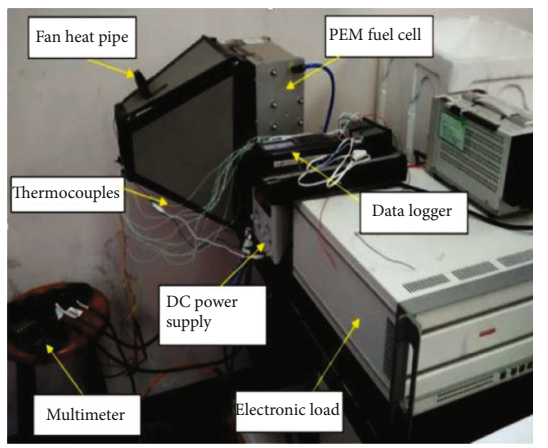

(d)

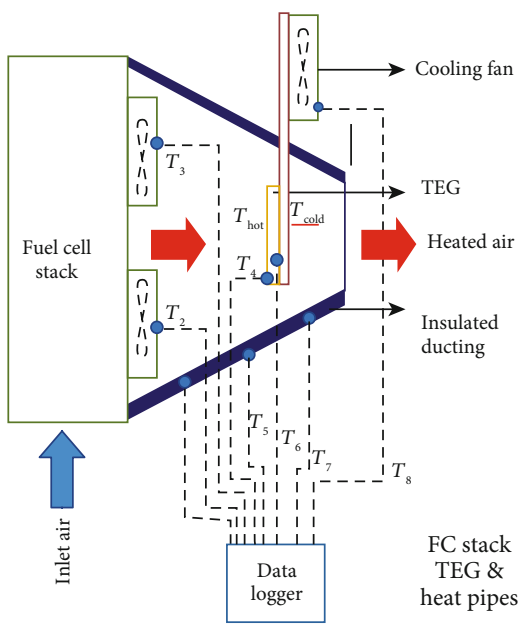

(b)

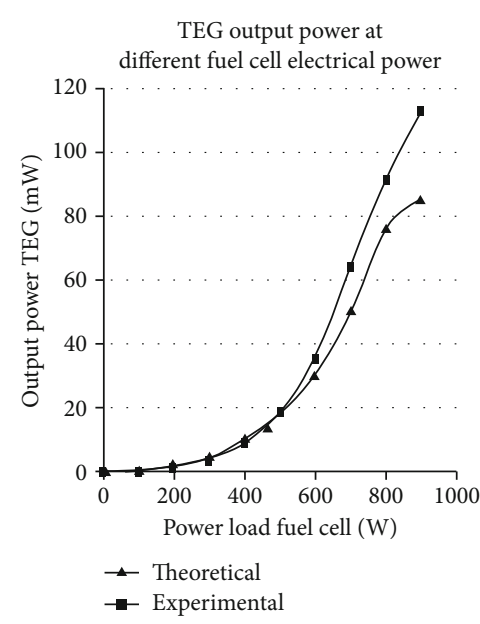

(c)

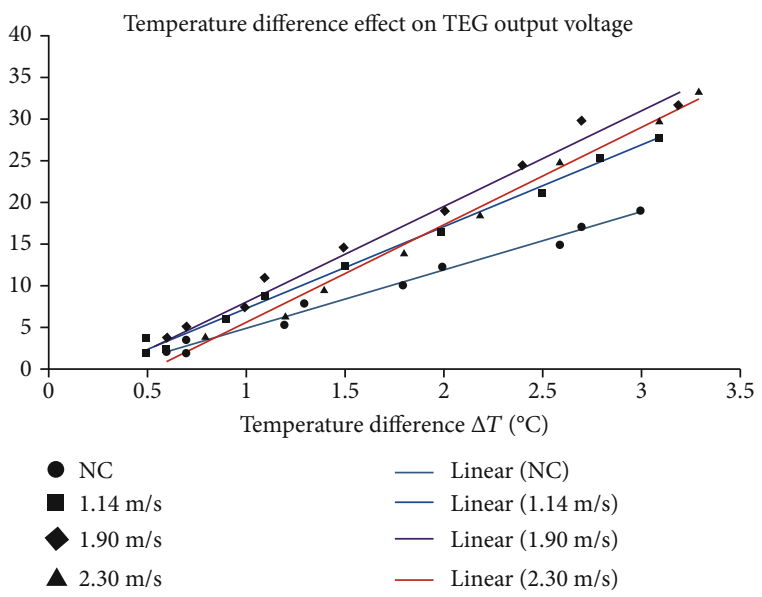

(e)

FIGURe 12: TEG and $1 \mathrm{~kW}$ LT-PEM FC waste heat recovery system (adapted from [14]).

production from the FC. Moreover, the experimental results obtained correlated the theoretical results. Figure 12 depicts the theoretical and experimental setups and the test results.

\subsection{TECs as TEGs with $5 \mathrm{~kW}$ LT-PEM FC CHP Waste Heat} Recovery. Presented in [15] is the experimental performance of TECs as TEGs (Figure 13(b)) in waste heat recovery system from a $5 \mathrm{~kW}$ LT-PEM FC (Figure 13(a)). The system setup (Figure 13(d)) constituted a thermoelectric heat recovery system (THRS; see Figure 13(e)) consisting of a heat exchanger (Figure 13(c)), four TECs (Figures 13(f) and 13(a)), and a typical heat-sink (Figure 13(e), 1) attached on the cold sides of the TEC $2 \times 2$ array. Figures $13(\mathrm{~g})$ to $13(\mathrm{j})$ display the various measured parameters as shown. The experiment outcomes showed that TECs as TEGs can be suitable to recover waste heat from a LT-PEM FC. The CHP system total efficiency decreased with increases in the outlet water temperatures due to low $\Delta T$; as a result, the TEG open circuit voltages decreased. Finally, to assess the useful output power, MPT occurred when the load resistance changed from 1 to $10 \Omega$.

2.14. Uninterrupted TE Energy Harvesting with Temperature Sensor-Based MPPT. Investigated in [23] is a thermoelectric generator energy harnessing system with a temperature sensor-based maximum power point tracking (MPPT) scheme. The perturb and observe (P\&O) technique is generally used in TEG applications but it responds poorly to a fast-changing power output. In addition, habitual MPPT algorithms for photovoltaic (PV) cells may not be appropriate for TEG power generation because an important amount of time is needed for TEG systems to reach a steady state. Furthermore, complexity and extra power consumptions in conventional circuits and periodic disconnections of power source are not desirable for low-power energy harvesting applications. The researched scheme in Figures 14(a) and 14(e)-14(g) can track the fluctuating maximum power point (MPP) with an easy and inexpensive temperature sensor- 


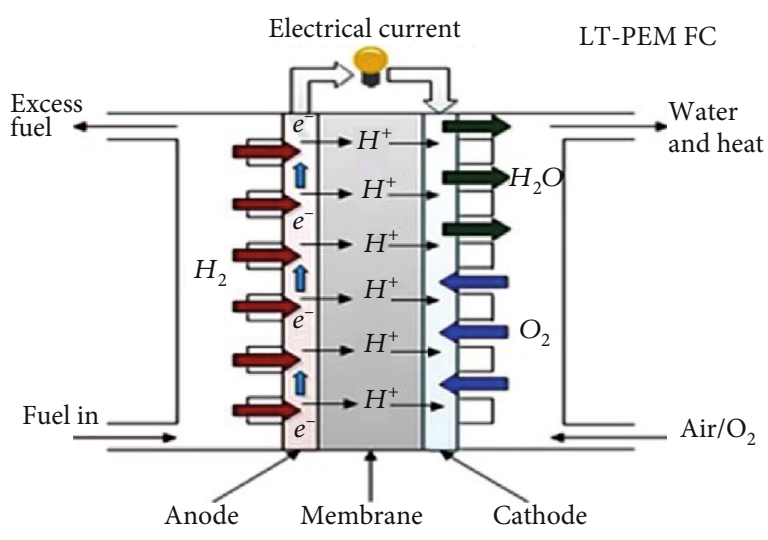

(a)

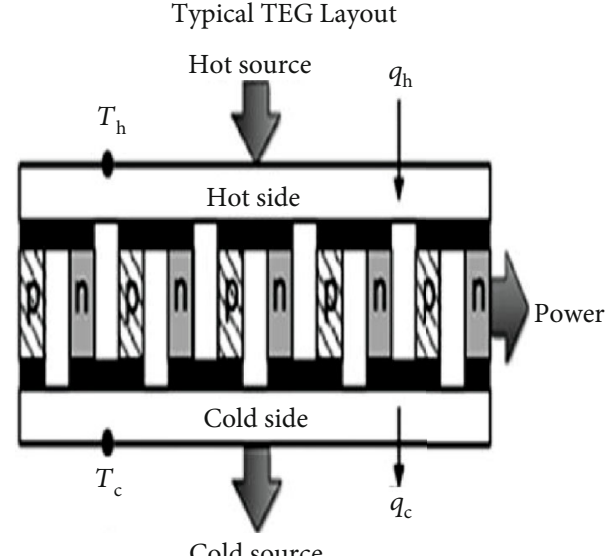

(b)

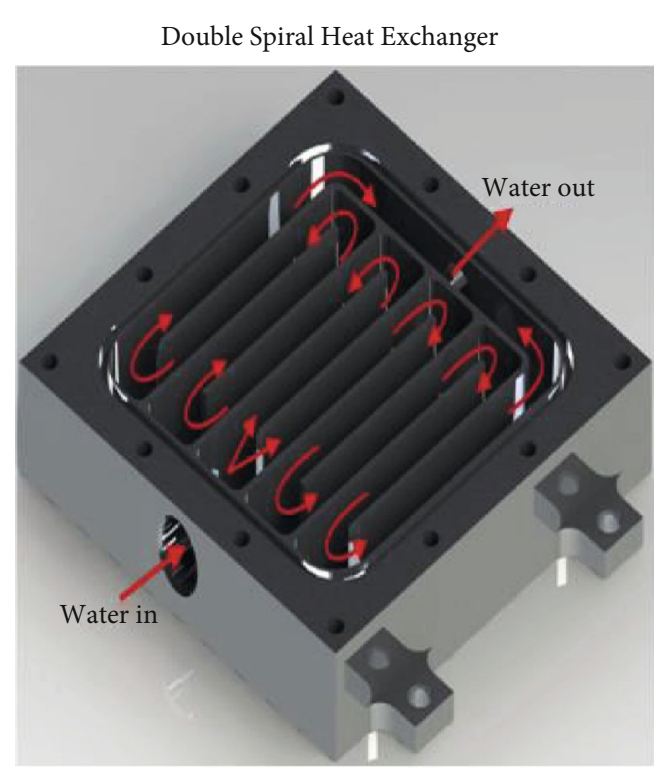

(c)

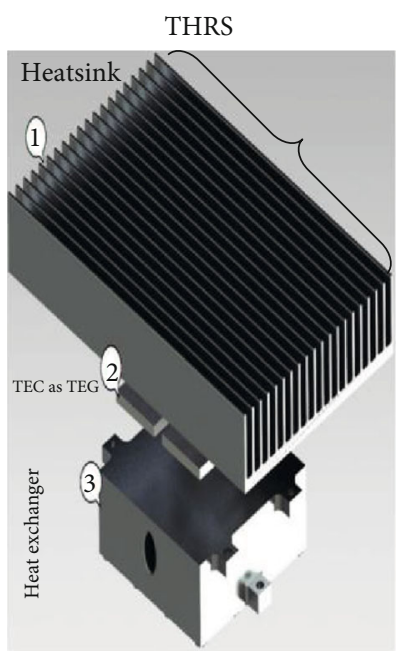

(e)

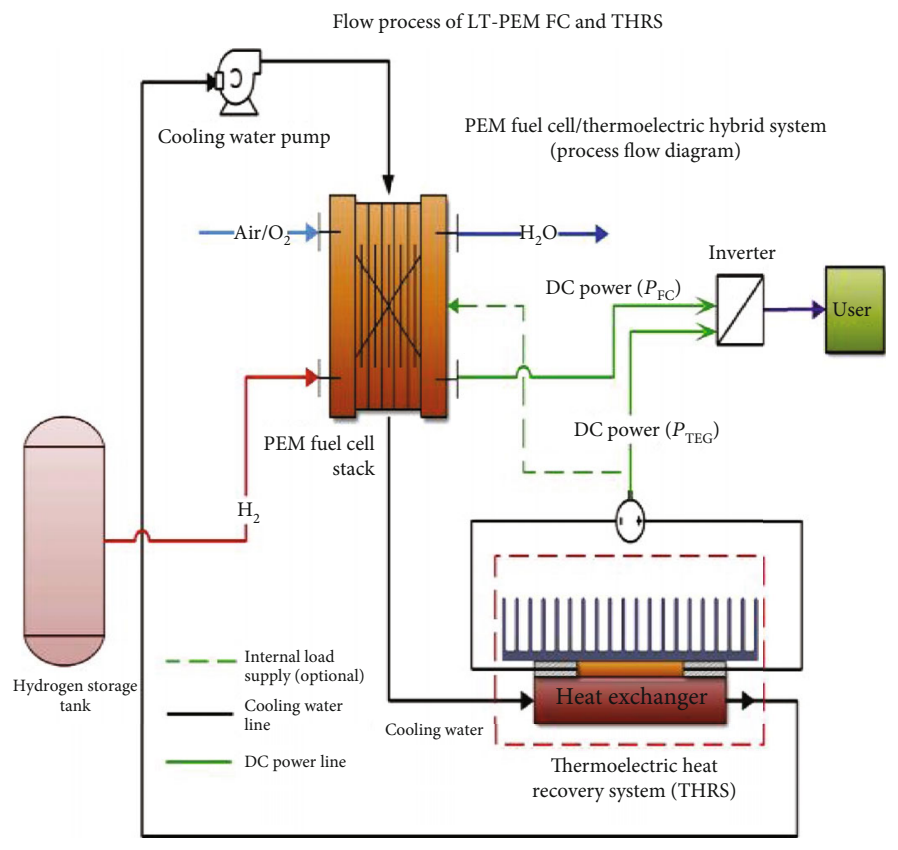

(d)

TECs as TEGs mounted on a heat exchanger

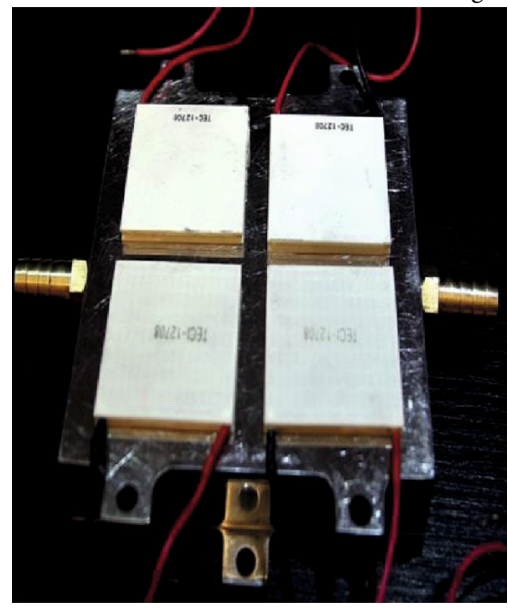

(f)

Figure 13: Continued. 

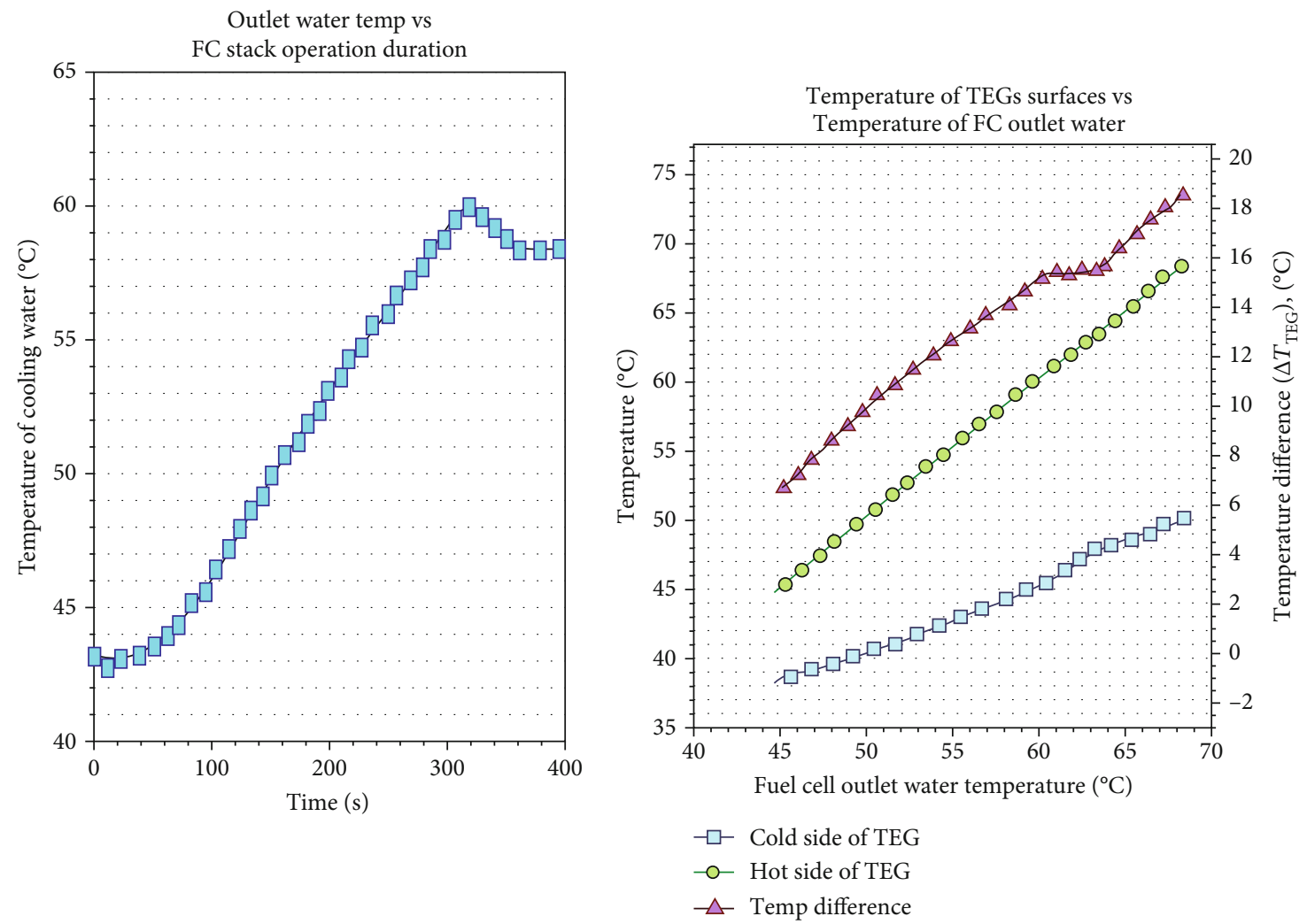

(g)
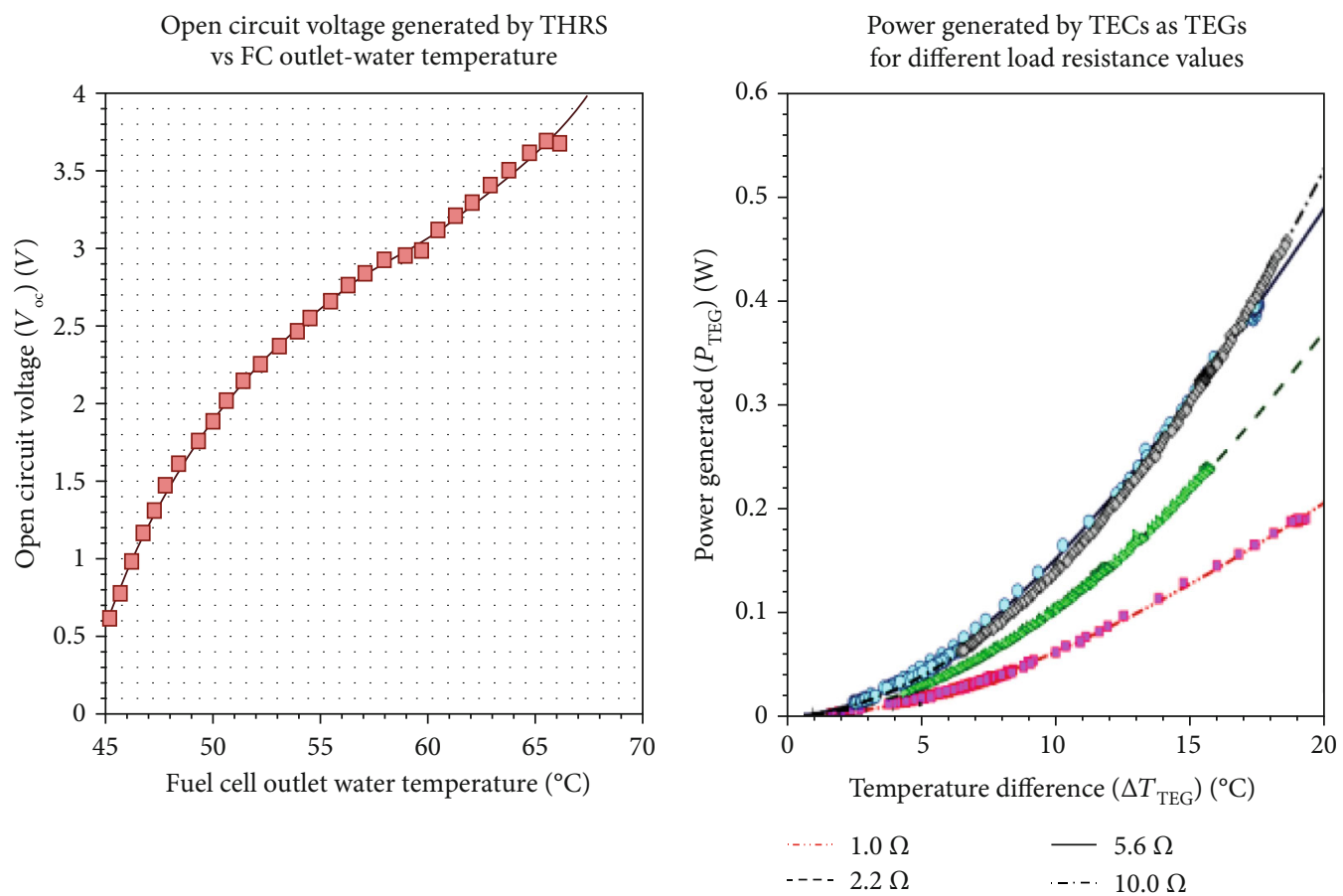

(i)

(j)

FIgURE 13: TECs as TEGs with $5 \mathrm{~kW}$ LT-PEM FC waste heat recovery system (adapted from [15]).

based circuit without instantaneous power measurement or TEG disconnections. This method used TEG's open circuit voltage $(\mathrm{OCV})$ attributes with respect to temperature gradient to generate a proper reference voltage signal that is half of the TEG's OCV. The boost power converter controller maintained the TEG output voltage at the reference level so that the maximum power can be extracted for the given temperature condition. This feed-forward MPPT approach 


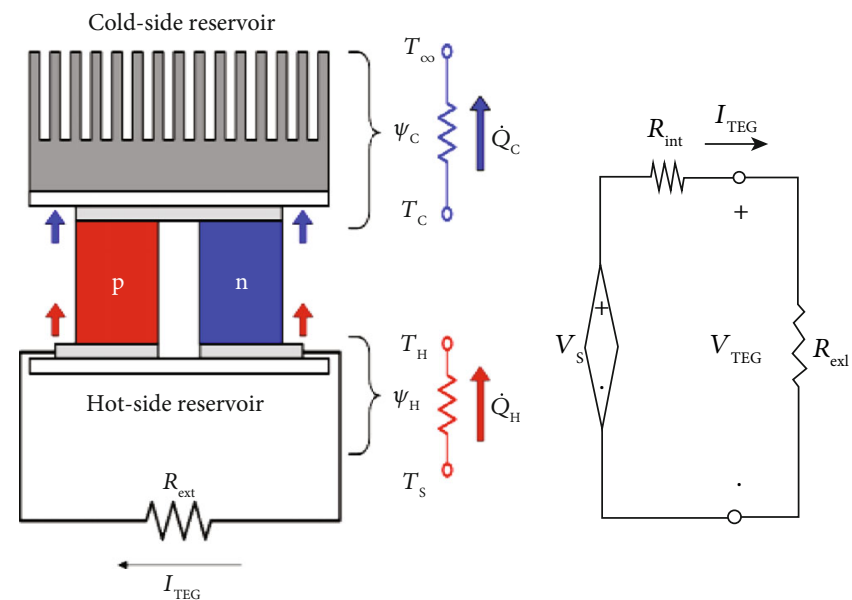

$\begin{array}{ll}\text { (a) TEG thermal model } & \text { (b) TEG electrical model }\end{array}$

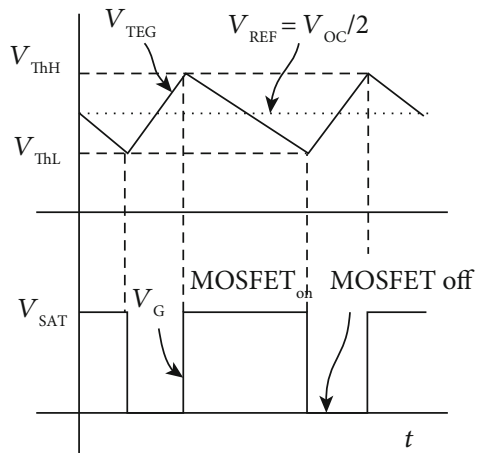

(c) TEG MPP operation with hysterisis

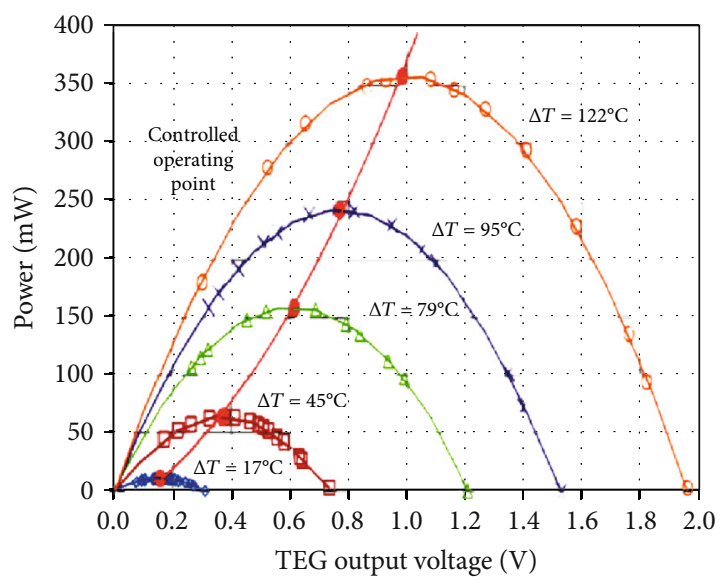

(d) Experimental result of MPPT control

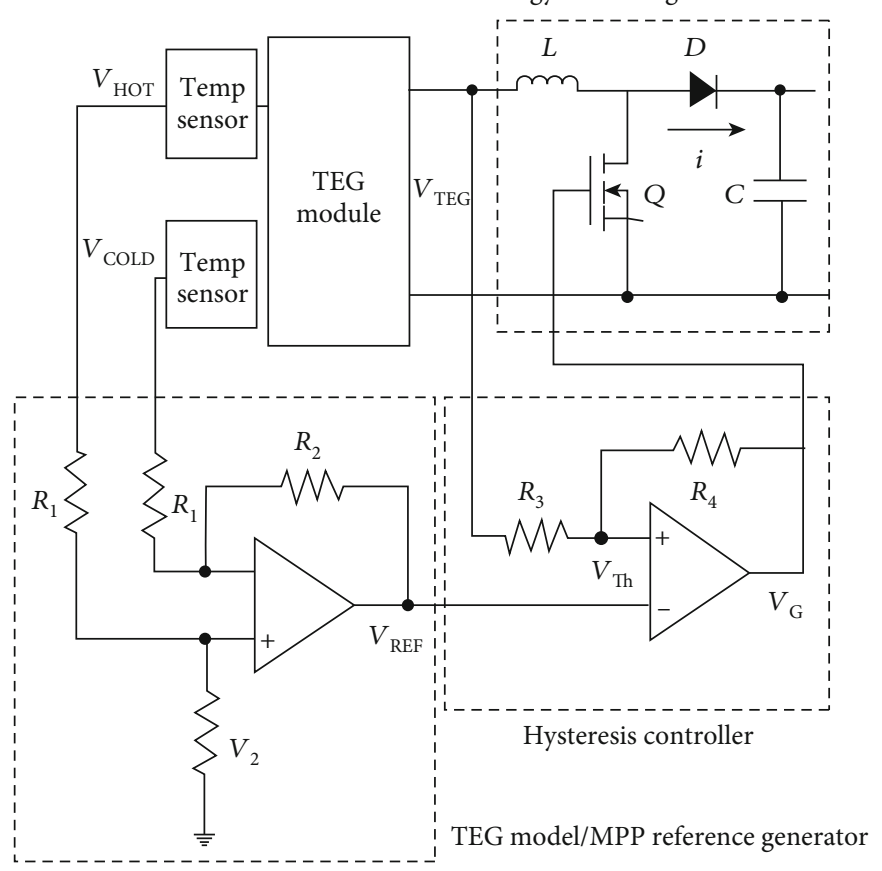

(e) Complete schemettic of the researched scheme

Figure 14: Continued. 


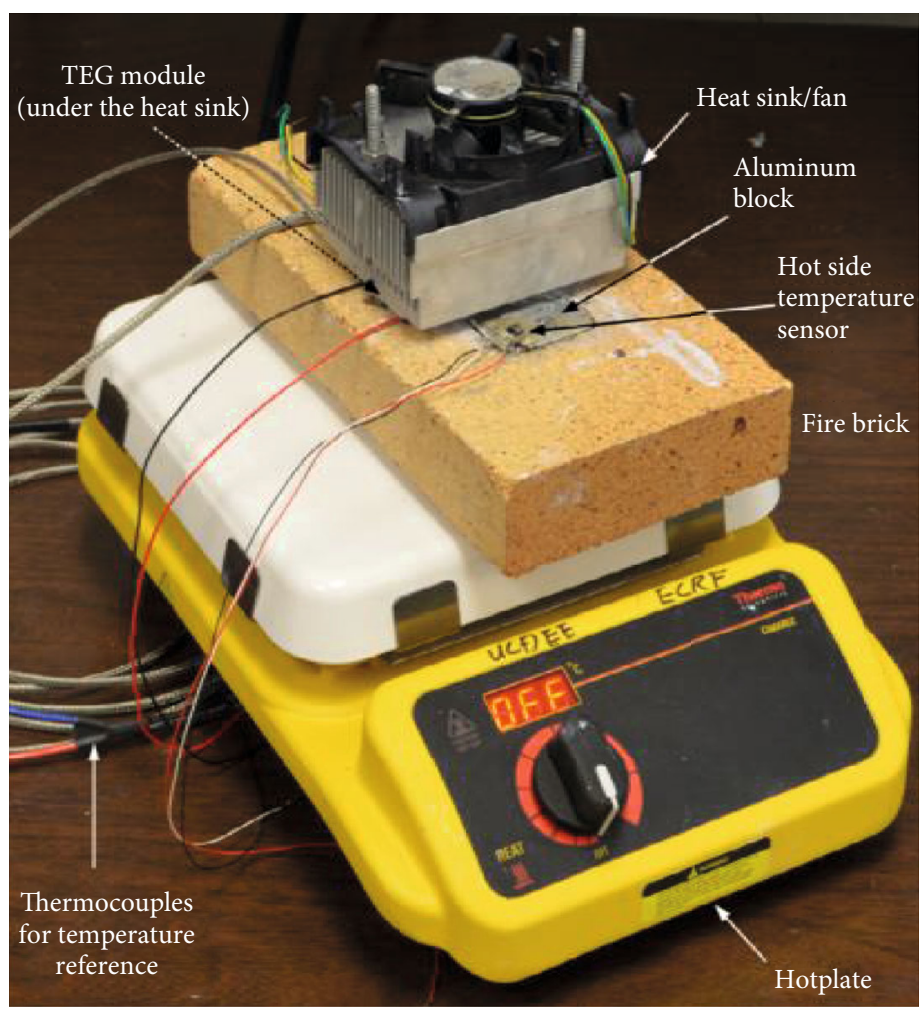

(f) TEG with MPPT scheme experimental setup

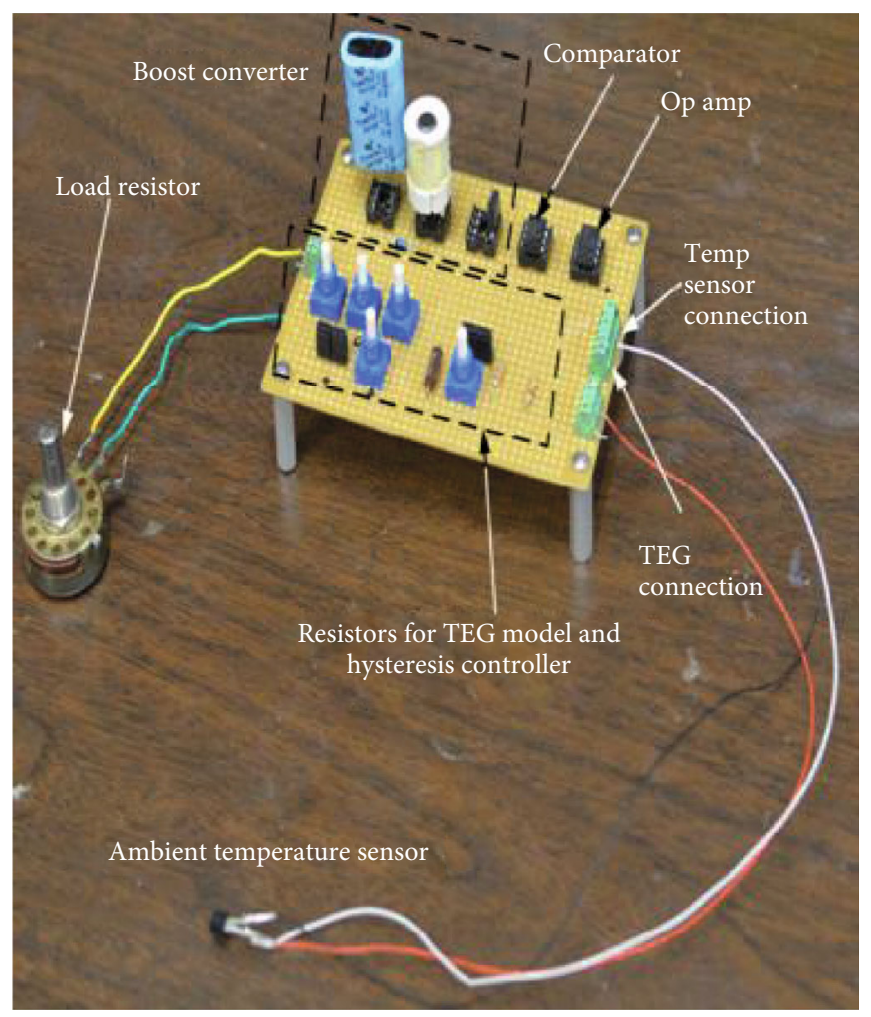

(g) TEG energy harvesting controller

FIGURE 14: Uninterrupted TE energy harvesting with temperature sensor-based MPPT (adapted from [23]).

is inherently stable and can be implemented without any complex microcontroller circuit. The investigated technique analytically and experimentally correlated and had a maxi- mum power tracking error of $1.15 \%$. Figure 14 (b) is a TEG equivalent circuit. Figures 14(c) and 14(d) show the operational waveforms. 


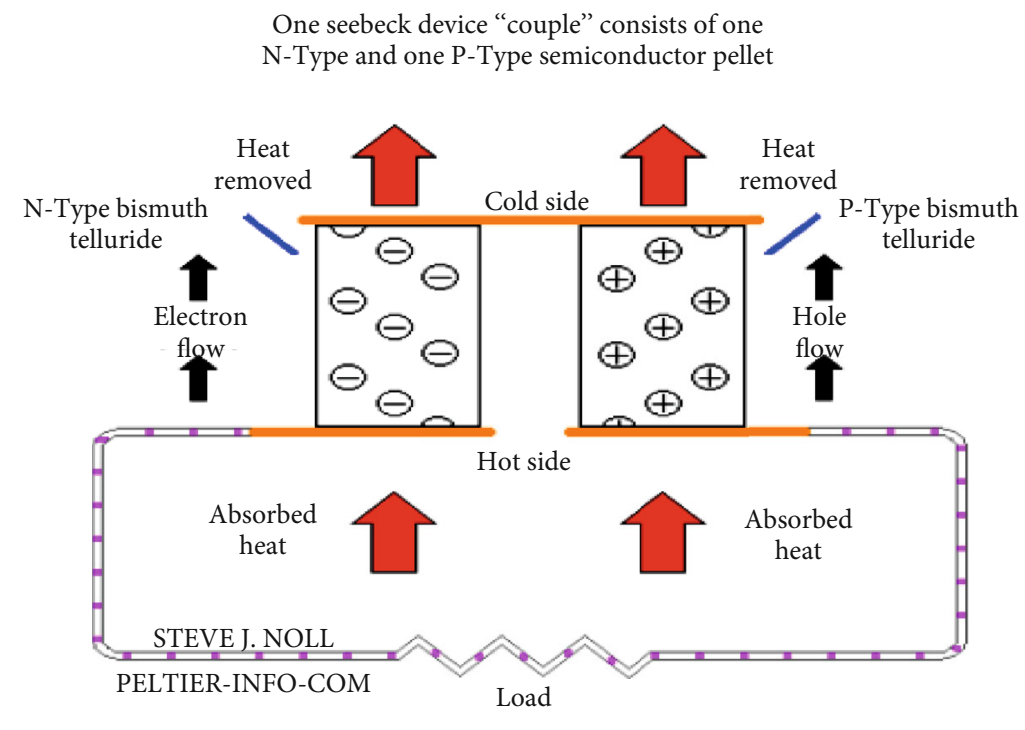

There must be a temperature difference between the hot and cold sides for power to be generated

(a) TEG seebeck effect principle
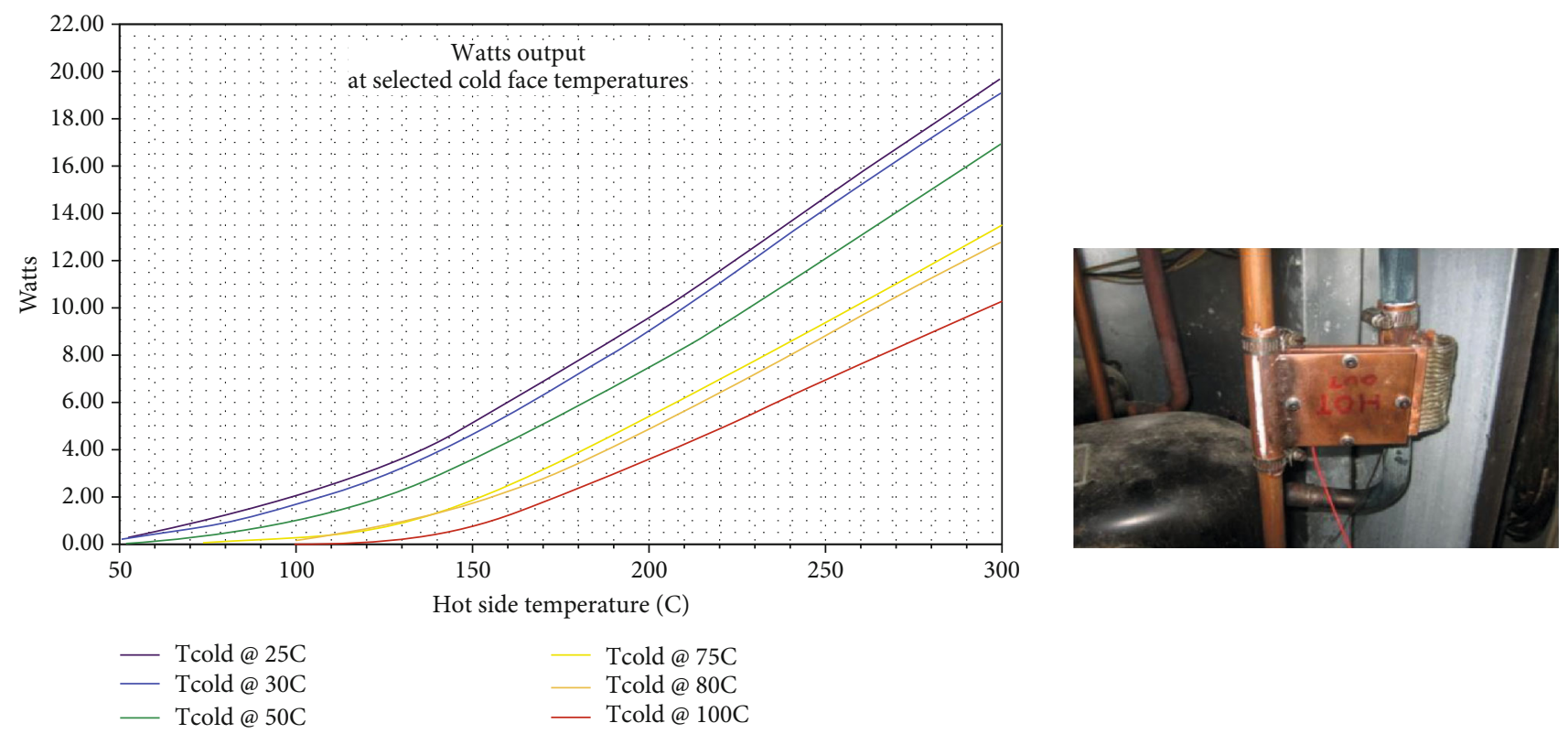

(b) TEG power output vs hot-side temperature

(c) TEG module clamped to a compressor hot pipes

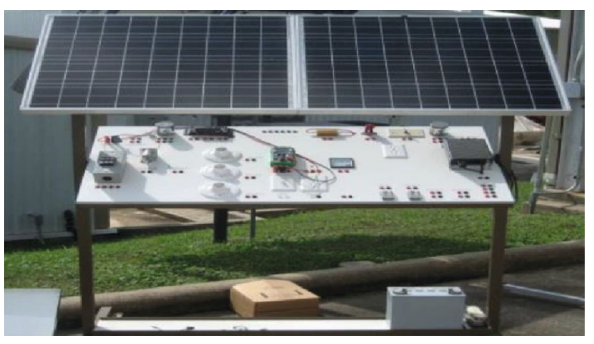

(d) Solar panels under test

\begin{tabular}{|c|c|c|c|c|c|c|c|c|c|}
\hline & $\begin{array}{c}\text { Cost } \\
\text { (each) } \\
(\$)\end{array}$ & $\begin{array}{c}\text { Cost } \\
(4) \\
(\$)\end{array}$ & $\begin{array}{c}\text { Size } \\
\text { (each) } \\
\text { (area } \\
\text { (sq. } \\
\text { in) }\end{array}$ & $\begin{array}{l}\text { Size } \\
(4) \\
\text { (sq. } \\
\text { in) }\end{array}$ & $\begin{array}{c}\text { Weight } \\
\text { (lbs) }\end{array}$ & $\begin{array}{c}\text { Weight } \\
\text { (4) } \\
\text { (lbs) }\end{array}$ & 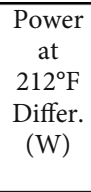 & $\begin{array}{c}\text { Power } \\
\text { at } \\
518^{\circ} \mathrm{F} \\
\text { Differ. } \\
\text { (W) }\end{array}$ & $\begin{array}{c}\text { Power } \\
\text { output } \\
\text { (1 solar) } \\
(4 \\
\text { TEGs) } \\
(\mathrm{W})\end{array}$ \\
\hline Solar & 250 & & 760 & & 18 & & & & 65 \\
\hline TEG & 99.75 & 400 & 5 & 20 & 0.14 & 0.56 & 3.54 & 19.1 & 76.4 \\
\hline
\end{tabular}

(e) Summary of TEG and solar panel test results

FigURE 15: TEG versus solar energy generations comparison (adapted from [24]).

2.15. TEG versus Solar Energy Generation Comparison. Examined in [24] is a comparison study of TEG and solar energy as shown in Figure 15(e). Figure 15(a) shows the
TEG concept. Figure 15(b) depicts the output power based on TEG temperature differences on both sides. The tested TEG hot side temperature ranged from 50 to $300^{\circ} \mathrm{C}$ and cold 
TEG Thevenin model: constant temperature difference

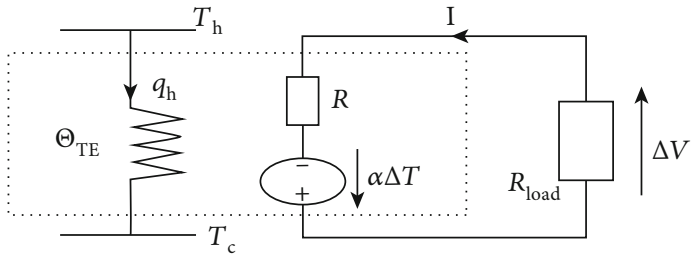

(a) TEG model with ideal thermal contacts to heat source

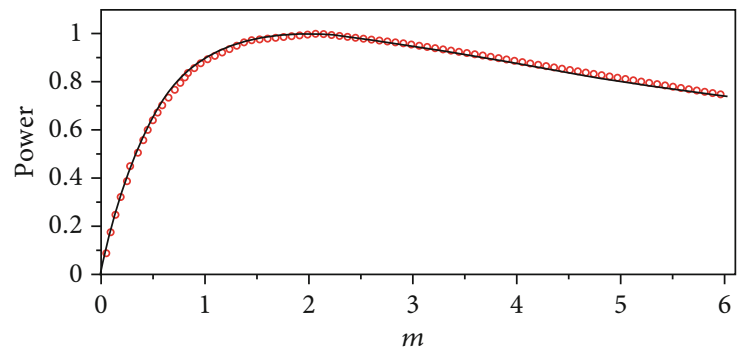

- Numerical

- Analytic

(c) Normalised output power as a function of maximization ratio (m)

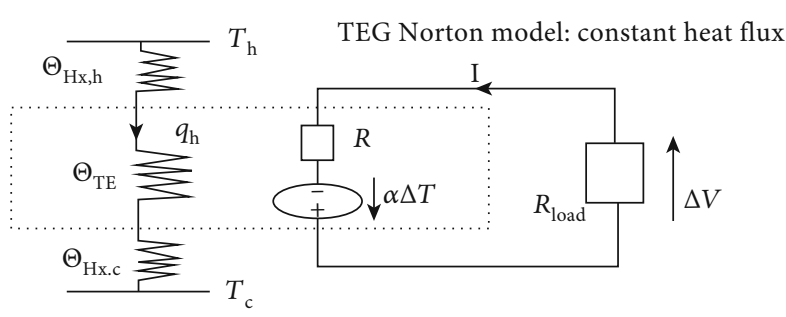

(b) TEG model with non-ideal thermal contacts to heat source

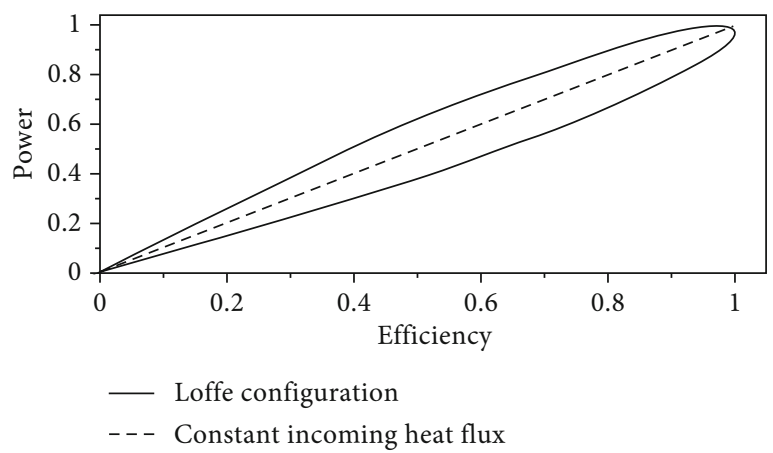

(d) Normalised output power as a function of normalised efficiency for both TEGs

FIGURE 16: Influence of thermal environment on optimal working conditions of TEGs (adapted from [27]).

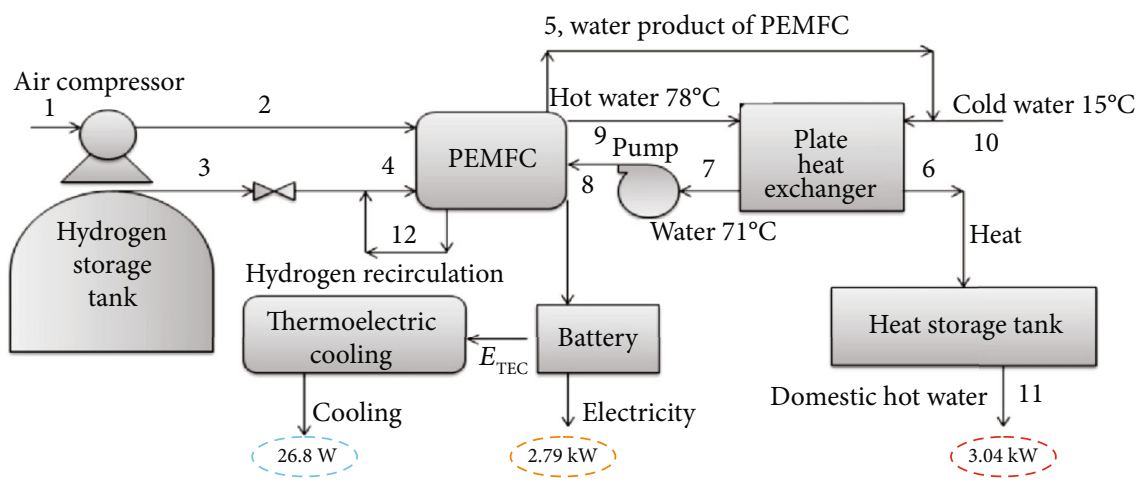

Figure 17: TEC and PEM fuel cell CCHP system (adapted from [25]).

side from 25 to $100^{\circ} \mathrm{C}$. The bigger the temperature difference, the more output power from the TEG. The TEG generated $\sim 20 \mathrm{~W}$ with a $275^{\circ} \mathrm{C}$ temperature difference-hot side temperature of $300^{\circ} \mathrm{C}$ and cold side $25^{\circ} \mathrm{C}$. Figures $15(\mathrm{c})$ and 15(d) show the TEG and solar test setups. It was concluded that size wise, a TEG module can generate more power relative to solar module; however, TEGs are more costly to generate the same amount of power. Also, TEGs need big $\Delta T$ to generate a reasonable power.

2.16. Influence of Thermal Environment on Optimal Working Conditions of TEGs. As established in [27], the Thevenin (Figure 16(a)) and Norton (Figure 16(b)) TEG models were used to show that the TEG output power and efficiency in a thermal environment can be simultaneously maximised if its heat flux is constant but not the case if its temperature difference is constant. Figures 16(c) and 16(d), respectively, depict the TEG normalised output power as a function of maximisation ratio and as a function of normalised efficiency for both TEGs (Figures 16(a) and 16(b)). The study concluded by suggesting a TEG power optimisation may be conducted in three steps: (i) choosing a TEG device or material with best $Z \bar{T}$ or $z \bar{T}$, (ii) use thermal impedance matching to determine TEG dimension, and (iii) use electrical impedance matching to determine the TEG load.

2.17. Thermoelectric Cooler (TEC) and LT PEM Fuel Cell CCHP System. According to [25], the prime mover is a LT PEM FC. A low-quality heat of $\sim 80^{\circ} \mathrm{C}$ and water condensate were recovered as the by-products. A thermoelectric cooler (TEC) was used as the cooling system. The mathematical models of the fuel cell and the thermoelectric cooler were implemented, and the results of simulations were confirmed with published data in the literature. The results validated a new micro CCHP system. The results showed that the cycle is capable of producing $2.79 \mathrm{~kW}$ of electricity, $3.04 \mathrm{~kW}$ of 


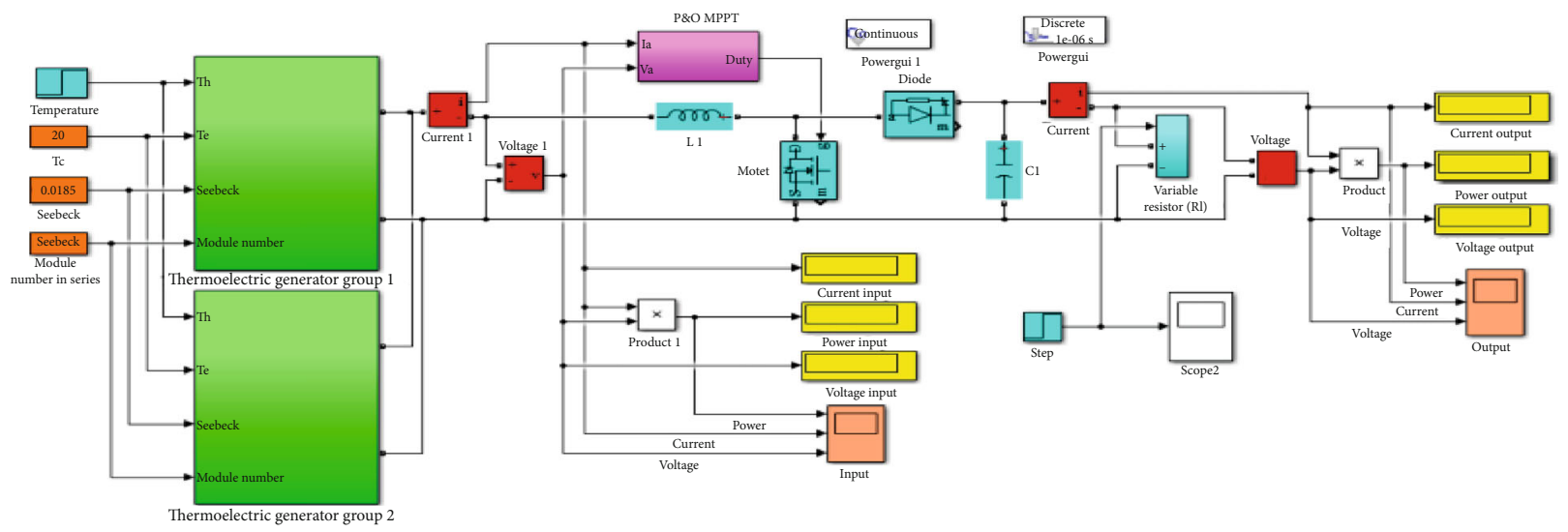

(a) TEG simulink model with a boost converter controlled by P\&O MPPT

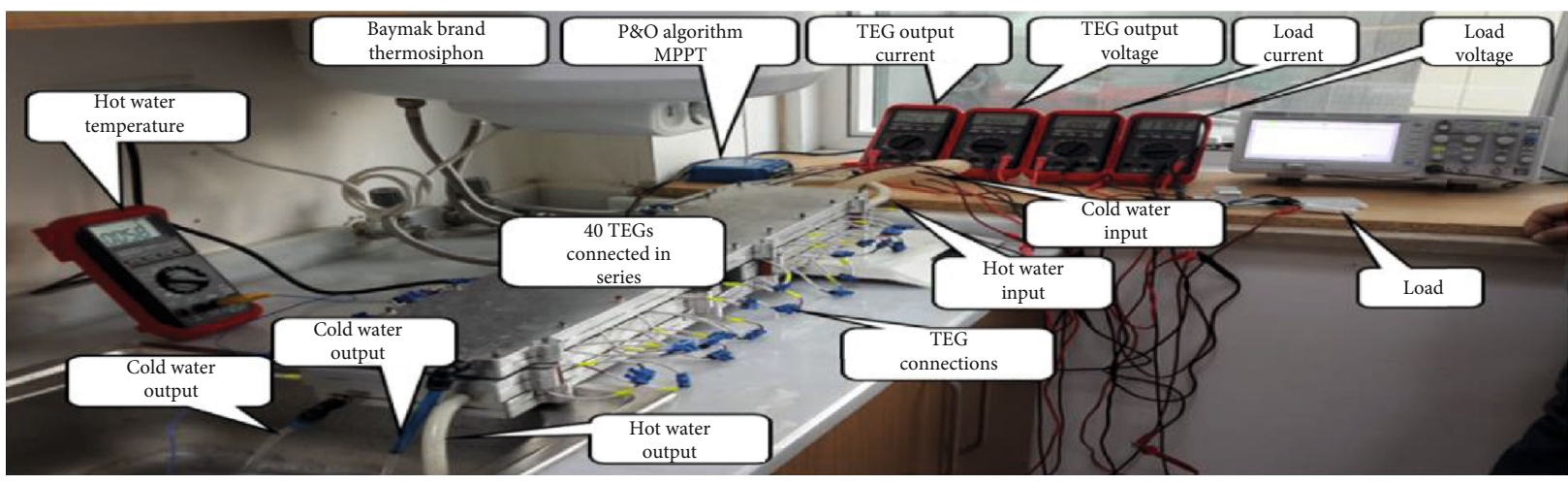

(b) TEG experimental setup
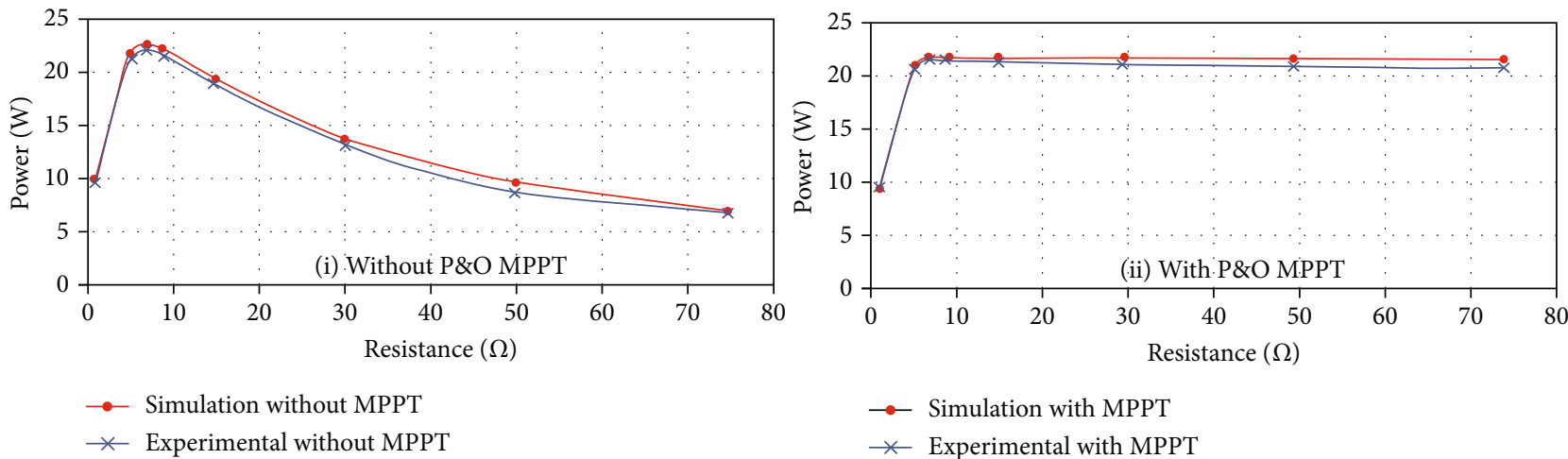

(c) TEG generated power as a function of the load variations (i) without P\&O MPPT and (ii) with P\&O MPPT

Figure 18: Simulated and experimental TEG, boost converter, and P\&O MPPT schemes (adapted from [50]).

heat, and $26.8 \mathrm{~W}$ of cooling with a total efficiency of the trigeneration cycle of $76.94 \%$ and fuel saving of $43.25 \%$. Figure 17 summarises the scheme.

2.18. Modelling of TEG and P\&O MPPT with Load and Temperature Variations. Investigated in [50], the maximum power is attained when the load connected to a TEG matches its internal resistance. However, impedance matching is not always practically guaranteed. As a result, in the setup as per Figure 18(a), MATLAB/Simulink was employed to model TEG, and the implementation was based on a TEG manufacturer's datasheets. TEGs were connected to a boost converter without MPPT using different loads, from which up to $98 \%$ of the TEG power was transferred to the load when matched with $\sim 7 \Omega$ but was not the case with other load values. In another run, P\&O MPPT algorithms were employed in the boost converter and its output was connected again to different loads and the generated power of $\sim 20 \mathrm{~W}$ was constant to loads from 7 up to $70 \Omega$ as shown in Figure 18(c). A similar setup was done with TEG hot side temperature $\left(T_{\text {hot }}\right)$ variations using a fixed cold side temperature of $20^{\circ} \mathrm{C}$ and it was realised that the output power efficiency was $<90 \%$ for $T_{\text {hot }}<70^{\circ} \mathrm{C}$. The proposed TEG, boost converter, and $\mathrm{P} \& \mathrm{O}$ MPPT models were validated with an experimental TEG system setup as demonstrated in Figure 18(b). 
TABLE 3: Summary of the eighteen thermoelectricity case studies reviewed.

\begin{tabular}{|c|c|c|}
\hline & Case studies analysed & Highlights, advantages and disadvantages \\
\hline [4] & Case study A (Bell, 2008) & $\begin{array}{l}\text { (i) the principle of thermoelectricity: construction, TEG, and TEC } \\
\text { (ii) } Z T \text { : TE device dimensionless figure of merit. More } Z T \text {, the better }\end{array}$ \\
\hline [3] & Case study B (Gao, 2014) & $\begin{array}{l}\text { Showed that TEG can be used as TERs to harvest exhaust heat and boost HT PEM FC } \\
\text { efficiency with emphasis on (i) heat exchanger surface type, (ii) its housing dimensions, and } \\
\text { (iii) power conditioning }\end{array}$ \\
\hline [2] & Case study C (Huston et al., 2004) & $\begin{array}{l}\text { (i) about } 40 \text { specific applications of TEG were researched and it was noticed that TEG form } \\
\text { factor is crucial to enable mounting anywhere } \\
\text { (ii) TEG was used with various FCs to boost output power by } 7-10 \%\end{array}$ \\
\hline [5] & Case study D (Zhao et al., 2016) & $\begin{array}{l}\text { Showed how energy was harnessed from intermittent heat sources and converted into } \\
\text { stored charge via the ionic Soret effect in an ITESC. Max efficiency is very low compared to } \\
\text { TEG of the same } Z T\end{array}$ \\
\hline [6] & Case study E (Mahmud et al., 2017) & $\begin{array}{l}\text { Demonstrated that TEGs connected in series and parallel generate more voltage and } \\
\text { current, respectively, that also increases with } T_{c}\end{array}$ \\
\hline [7] & Case study F (Qu et al., 2018) & $\begin{array}{l}\text { Developed a thermodynamic model for the TEG and microturbine. Showed that TEG } \\
\text { almost doubled the hybrid CHP output power }\end{array}$ \\
\hline [8] & Case study G (Katkus, 2015) & $\begin{array}{l}\text { The manufacturing of a TEG involve choosing a TE material with good } Z T(>1) \text {, electrodes } \\
\text { insulating plate, adhesives, and module architecture. A real system was built to characterise } \\
\text { TEG modules }\end{array}$ \\
\hline [20] & Case study H (Sullivan, 2012) & $\begin{array}{l}\text { Modelled TEGs and TECs on a chip. TECs are more efficient using more and better if } \\
\text { operated at a steady state for frequent hotspots. For infrequent hotspots, TECs may be } \\
\text { cooled with square root transient pulses of a very short duration. TEG MPT occurred at } \\
\text { greater load resistance. TEG useful power is firstly linear and later parabolically } \\
\text { proportional to the heat flux. More TEGs increase output power but decrease later. Thinner } \\
\text { TIM improves TEC and TEG capabilities }\end{array}$ \\
\hline$[10]$ & Case study I (Teffah et al., 2018) & $\begin{array}{l}\text { TEC was used as a TEG cooler in simulated and practical setups. The } \Delta T \text { was directly } \\
\text { proportional to the TEC } V_{\text {in }} \text { and TEG } V_{\text {out }}\end{array}$ \\
\hline$[21,22]$ & Case study J (Stockholm, 2016) & $\begin{array}{l}\text { Demonstrated that the output power from TEG when pulsed doubles the conversion } \\
\text { efficiency. An } 8.4 \% \text { increase was attained }\end{array}$ \\
\hline [9] & Case study K (Kiziroglou et al., 2016) & $\begin{array}{l}\text { Proved that thicker TEGs with good area coverage can be used to harvest electricity from } \\
\text { the environment with fluctuating temperatures }\end{array}$ \\
\hline$[14]$ & Case study L (Sulaiman et al., 2017) & $\begin{array}{l}\text { Showed the use of a TEG with FC under simulated natural (static) and forced convection } \\
\text { cooling (dynamic) to convert heat to power } \\
\text { However, very high } \Delta T \text { is required to generate significant power }\end{array}$ \\
\hline [15] & $\begin{array}{l}\text { Case study M (Hasani and Rahbar, } \\
\text { 2015) }\end{array}$ & $\begin{array}{l}\text { Demonstrated the duality of TECs as TEGs in a FC CHP using a THRS. Low } \Delta T \text { gave low } \\
V_{\text {out }} \text {. MPT occurred at } R_{\text {load }} \text { of } 1-10 \Omega\end{array}$ \\
\hline [23] & Case study N (Park et al., 2014) & $\begin{array}{l}\text { Showed the use of a low-cost microcontroller and temperature sensor-based circuit, to } \\
\text { track TEG MPP with a } 1.1 \% \text { tracking error }\end{array}$ \\
\hline$[24]$ & Case study O (Yildiz et al., 2013) & $\begin{array}{l}\text { Compared TEG and solar energy conversion. A TEG generates more power relative to solar } \\
\text { module of same size but more costly }\end{array}$ \\
\hline [27] & Case study P (Apertet et al., 2014) & $\begin{array}{l}\text { Deduced that a TEG output power and efficiency in a thermal environment can be } \\
\text { simultaneously maximised if its heat flux is constant but not the case if its temperature } \\
\text { difference is constant }\end{array}$ \\
\hline [25] & $\begin{array}{l}\text { Case study Q (Ebrahimi and } \\
\text { Derakhshan, 2018) }\end{array}$ & $\begin{array}{l}\text { Proved that a TEC LT-PEM FC hybrid CCHP system is capable of producing } 2.79 \mathrm{~kW} \text { of } \\
\text { electricity, } 3.04 \mathrm{~kW} \text { of heat, and } 26.8 \mathrm{~W} \text { of cooling with a total efficiency of } \sim 77 \% \text { and fuel } \\
\text { saving of } 43.25 \%\end{array}$ \\
\hline$[50]$ & $\begin{array}{l}\text { Case study R (Mamur and Çoban, } \\
\text { 2020) }\end{array}$ & $\begin{array}{l}\text { TEGs have no moving parts, have long service life, operate quietly, and are green. TEGs } \\
\text { have low efficiency and are expensive. By using the manufacturer datasheets, TEGs were } \\
\text { modelled, simulated, experimented, and result correlated. Impedance matching with boost } \\
\text { converter and P\&O MPPT schemes gave } 98.64 \% \text { efficiency }\end{array}$ \\
\hline
\end{tabular}

\section{Summary of the Eighteen Thermoelectricity Case Studies Examined}

Table 3 presents the highlights of each case study as well as the pros and cons where applicable.

\section{Conclusion}

Energy security and electricity crisis in particular is an ongoing pressing societal problem in South Africa. In light of this, this paper presented a structural review of 18 
assorted thermoelectricity applicable studies, to best devise a hybrid CCHP system for domestic/commercial applications. To achieve this, diverse analyses on past research on thermoelectricity were examined, in which case studies related to co-/trigeneration with fuel cells were of most interest. In these studies, thermoelectricity increased the power efficiency by converting waste heat into electricity as TEGs and electricity into cold as TECs. Also examined was how ionic thermoelectricity exhibits supercapacitor properties and in conclusion was a TEC and PEMFC hybrid CCHP system study, where the PEMFC was the prime mover and TEC was the cooler, capable of generating $2.79 \mathrm{~kW}$ of electricity, $3.04 \mathrm{~kW}$ of heat, and $26.8 \mathrm{~W}$ of cold, having a total efficiency of $\sim 77 \%$ and fuel saving of $43.25 \%$. The relevant highlights, advantages, and disadvantages of the eighteen case studies examined were summarised as the key findings and contributions brought forward. As a result, an alternative research model incorporating thermoelectricity for use with FC in CCHP applications and to address the FC fuel starvation phenomenon is doable and shall be researched.

\section{Glossary}

$\Delta T: \quad$ Temperature difference between hot and cold sides of a thermoelectric device in Kelvin or Celsius

$\sigma: \quad$ Electrical conductivity (Siemens $/ \mathrm{m}$ ) is the

$\eta_{\max }:$ inverse of electrical resistivity $\rho(\Omega . \mathrm{m})$

$\eta_{\text {TEG }}$ :

$S^{2} \sigma:$

TEG maximum efficiency determined by $Z T$

TEG thermal or electrical or conversion efficiency

AC: Known as TEG electrical power factor $\left(\mathrm{W} / \mathrm{mK}^{2}\right)$

AC: $\quad$ Alternating current

CCHP: Combined cooling heating and power

CHP: $\quad$ Combined heat and power

COP: $\quad$ Coefficient of performance

CPUT: $\quad$ Cape Peninsula University of Technology

DC: $\quad$ Direct current

DoD: $\quad$ Department of Defence

FC: $\quad$ Fuel cell

HF: $\quad$ High frequency

HSU: $\quad$ Heat storage unit

HT PEM FC: High-temperature polymer electrolyte membrane fuel cell

I: $\quad$ Electrical current (A)

ITESC: Ionic thermoelectric supercapacitor

$k$ : $\quad$ Thermal conductivity $(\mathrm{W} / \mathrm{mK})$

$k_{e}: \quad$ Thermal conductivity charge carrier contribution $(\mathrm{W} / \mathrm{mK})$

K: $\quad$ Thermal conductance $(\mathrm{W} / \mathrm{K})$

LF: $\quad$ Low frequency

LGH: $\quad$ Low-grade heat

$L_{\mathrm{o}}$ : $\quad$ Constant known as the Lorenz number $\left(2.44 \times 10^{-8} \mathrm{~W} \Omega \mathrm{K}^{-2}\right)$

LT PEM FC: Low-temperature polymer electrolyte membrane fuel cell

MPT: $\quad$ Maximum power transfer

MPPT: $\quad$ Maximum power point tracking $n: \quad$ P-N thermocouple amount

OCV: Open circuit voltage

P\&O: $\quad$ Perturb and observe

PCM: $\quad$ Phase change material

PEM: $\quad$ Polymer electrolyte membrane or proton exchange membrane

PV: $\quad$ Photovoltaic

$Q_{h}: \quad$ The heat absorbed at TEG hot junction (W)

$R: \quad$ P-N thermocouple electrical resistance $(\Omega)$

$S$ : $\quad$ Seebeck's voltage per unit of temperature in Kelvin (V/K)

T: $\quad$ Absolute temperature in Kelvin $(273.15 \mathrm{~K})$ or $0^{\circ}$ Celsius

$\bar{T}: \quad$ Average temperature in Kelvin

$T_{\mathrm{c}}$ : $\quad$ Temperature on thermoelectric device or

material cold side (Kelvin or Celsius)

$T_{\mathrm{h}}$ : Temperature on thermoelectric device or material hot side (Kelvin or Celsius)

TE: Thermoelectric

TEC: $\quad$ Thermoelectric cooler

TEC $_{\mathrm{COP}}$ : $\quad$ TEC coefficient of performance

TEG: Thermoelectric generator

TEG $\mathrm{P}_{\text {Pout }}$ : $\quad$ TEG generated electrical output power delivered to the load (W)

TER: Thermoelectric heat-flux regulator

THRS: $\quad$ Thermoelectric heat recovery system

TIM: $\quad$ Thermal interface material

$Z: \quad \quad \quad \quad \quad \quad \quad$ TE device figure of merit measured in $\mathrm{K}^{-1}$

$z: \quad$ TE material figure of merit measured in $\mathrm{K}^{-1}$

ZT: $\quad$ TE device dimensionless figure of merit at absolute temperature $(273.15 \mathrm{~K})$

$Z \bar{T}: \quad \quad \quad \quad \quad \quad \quad$ EE device dimensionless figure of merit at temperature $\bar{T}$

$z T: \quad$ Thermoelectric material dimensionless figure of merit at absolute temperature $\left(0^{\circ} \mathrm{Celsius}\right)$.

\section{Data Availability}

The data of the research is still in use for the researchers; releasing data at this stage might result in the utilisation of data for research purposes by others. The sharing of data resources is currently limited to the researchers involved.

\section{Conflicts of Interest}

The authors declare that there is no conflict of interest regarding the publication of this paper.

\section{Acknowledgments}

The study was supported by the HySA Systems.

\section{References}

[1] D. Bessarabov, G. Human, A. J. Kruger et al., "South African hydrogen infrastructure (HySA infrastructure) for fuel cells and energy storage: overview of a projects portfolio," International Journal of Hydrogen Energy, vol. 42, no. 19, pp. 1356813588, 2017. 
[2] J. Huston, C. Wyatt, C. Nichols, J. M. Binder, and F. H. Holcomb, Application of Thermoelectric Devices to Fuel Cell Power Generation: Demonstration and Evaluation, US Army Corps of Engineers, Engineer Research and Development Centre, Washington DC, USA, 2004.

[3] X. Gao, HT-PEM fuel cell system with integrated thermoelectric exhaust heat recovery, Department of Energy Technology Aalborg University, Denmark, 2014, PhD Thesis.

[4] L. E. Bell, "Cooling, heating, generating power and recovering waste heat with thermoelectric systems," Science, vol. 321, no. 5895, pp. 1457-1461, 2008.

[5] D. Zhao, H. Wang, K. Z. Ullah et al., "Ionic thermoelectric super-capacitors," Energy \& Environmental Science, vol. 9, no. 4, pp. 1450-1457, 2016.

[6] K. H. Mahmud, S. A. Yudistirani, and A. I. Ramadhan, "Analysis of power characteristics of model thermoelectric generator (TEG) small modular," International Journal of Scientific \& Technology Research, vol. 6, no. 4, 2017.

[7] Z. Qu, T. Ma, X. Yu, and Q. Wang, "Parametric study on thermoelectric power generator and micro-turbine combined power generation system," Chemical Engineering Transactions, vol. 70, 2018.

[8] T. Katkus, "Design and construction of high temperature thermoelectric power generator module characterisation system [PhD Thesis]," Institute for Superconducting and Electronic Materials, University of Wollongong, Australia, 2015, http:// ro.uow.edu.au/theses/4499.

[9] M. E. Kiziroglou, T. Becker, S. W. Wright, E. M. Yeatman, J. W. Evans, and P. K. Wright, "Thermoelectric generator design in dynamic thermoelectric energy harvesting," Journal of Physics: Conference Series, vol. 773, no. 2016, article 012025, 2016.

[10] K. Teffah, Y. Zhang, and X. Mou, "Modeling and experimentation of new thermoelectric cooler-thermoelectric generator module," Energies, vol. 11, no. 3, p. 576, 2018.

[11] O. H. Ando Junior, N. H. Calderon, and S. S. De Souza, "Characterization of a thermoelectric generator (TEG) system for waste heat recovery," Energies, vol. 11, no. 6, p. 1555, 2018.

[12] J. Stockholm, C. Goupil, P. Maussion, and H. Ouerdane, "Transient thermoelectric generator: an active load story," Journal of Electronic Materials, Institute of Electrical and Electronics Engineers, vol. 44, no. 6, pp. 1768-1772, 2015.

[13] W. Chen and Y. Lin, "Performance comparison of thermoelectric generators using different materials," in 10th International Conference on Applied Energy (ICAE2018), Hong Kong, China, August 2018.

[14] M. S. Sulaiman, W. A. Mohamed, B. Singh, and M. F. Ghazali, "Validation of a waste heat recovery model for a $1 \mathrm{~kW}$ PEM fuel cell using thermoelectric generator," IOP Conference Series: Materials Science and Engineering, vol. 226, article 012148, 2017.

[15] M. Hasani and N. Rahbar, "Application of thermoelectric cooler as a power generator in waste heat recovery from a PEM fuel cell - an experimental study," International Journal of Hydrogen Energy, vol. 40, no. 43, pp. 15040-15051, 2015.

[16] R. J. Parise and G. F. Jones, "Fuel cell thermal management with thermoelectric coolers," in 37th Inter-society Energy Conversion Engineering Conference (IECEC), Washington, WA, USA, USA, July 2002.
[17] X. Chen, Y. Wang, L. Cai, and Y. Zhou, "Maximum power output and load matching of a phosphoric acid fuel cell- thermoelectric generator hybrid system," Journal of Power Sources, vol. 294, pp. 430-436, 2015.

[18] N. Rahbar and A. Asadi, "Solar intensity measurement using a thermoelectric module; experimental study and mathematical modeling," Energy Conversion and Management, vol. 129, pp. 344-353, 2016.

[19] Z. Shen, S. Wu, and L. Xiao, "Theoretical analysis on the performance of annular thermoelectric couple," Energy Conversion and Management, vol. 89, pp. 244-250, 2015.

[20] O. A. Sullivan, Embedded thermoelectric devices for on-chip cooling and power generation, Georgia Institute of Technology, Atlanta, USA, 2012, MSc Thesis.

[21] J. G. Stockholm, Non-Stationary Thermoelectric Generators, IntechOpen, London, UK, 2016.

[22] J. Stockholm, K. Wojciechowski, J. Leszczynski, K. Witek, P. Guzdek, and J. Kulawik, "Thermoelectric generator with an active load," Materials Today: Proceedings, vol. 2, no. 2, pp. 744-750, 2015.

[23] J. Park, H. Lee, and M. Bond, "Uninterrupted thermoelectric energy harvesting using temperature-sensor-based maximum power point tracking system," Energy Conversion and Management, vol. 86, pp. 233-240, 2014.

[24] F. Yildiz, K. L. Coogler, and B. Crockford, An applied comparison study: solar energy vs thermoelectric energy, 120th ASEE Annual Conference \& Exposition, 2013.

[25] M. Ebrahimi and E. Derakhshan, "Design and evaluation of a micro combined cooling, heating, and power system based on polymer exchange membrane fuel cell and thermoelectric cooler," Energy Conversion and Management, vol. 171, pp. 507-517, 2018.

[26] H. Goldsmid, "Conversion efficiency and figure-of-merit," CRC Handbook of Thermoelectrics, pp. 19-25, 1995.

[27] Y. Apertet, H. Ouerdane, C. Goupil, and P. Lecoeur, "Influence of thermal environment on optimal working conditions of thermoelectric generators," Journal of Applied Physics, vol. 116, no. 14, p. 144901, 2014.

[28] C. B. Vining, "An inconvenient truth about thermoelectrics," Nature Materials, vol. 8, no. 2, pp. 83-85, 2009.

[29] H. Lee, Thermal Design: Heat Sinks, Thermoelectrics, Heat Pipes, Compact Heat Exchangers and Solar Cells, John Wiley \& Sons, Inc., 2010, Wiley, New Jersey, USA, 1st edition, 2010.

[30] A. F. Ioffe, Semiconductor Thermoelements and Thermoelectric Cooling, Infosearch Limited, London, UK, 1957.

[31] A. Elarusi, A. Attar, and H. Lee, "Optimal design of a thermoelectric cooling/heating system for Car seat climate control (CSCC)," Journal of Electronic Materials, vol. 46, no. 4, pp. 1984-1995, 2017.

[32] W. Wang, V. Cionca, N. Wang, M. Hayes, B. O’Flynn, and C. O'Mathuna, "Thermoelectric energy harvesting for building energy management wireless sensor networks.," International Journal of Distributed Sensor Networks, vol. 9, no. 6, 2013.

[33] S. Twaha, J. Zhu, Y. Yan, and B. Li, "A comprehensive review of thermoelectric technology: Materials, applications, modelling and performance improvement," Modelling and Performance Improvement. Renewable and Sustainable Energy Reviews, vol. 65, pp. 698-726, 2016.

[34] Y. Xing, R. Liu, J. Liao et al., "High-efficiency half-Heusler thermoelectric modules enabled by self-propagating synthesis 
and topologic structure optimization," Energy \& Environmental Science, vol. 12, no. 11, pp. 3390-3399, 2019.

[35] H. Lee, Thermoelectrics: Design and Materials, John Wiley Inc., New Jersey, USA, 2016.

[36] S. Li, K. H. Lam, and K. Cheng, "The thermoelectric analysis of different heat flux conduction materials for power generation board," Energies, vol. 10, no. 11, p. 1781, 2017.

[37] M. O. Cernaianu and A. Gontean, "Parasitic elements modelling in thermoelectric modules," IET Circuits Devices Systems, vol. 7, no. 4, pp. 177-184, 2013.

[38] H. L. Tsai and J. M. Lin, "Model building and simulation of thermoelectric module using Matlab/Simulink," Journal of Electronic Materials, vol. 39, no. 9, pp. 2105-2111, 2010.

[39] M. A. Musleh, E. Topriska, L. Jack, and D. Jenkins, "Thermoelectric generator experimental performance testing for wireless sensor network application in smart buildings," MATEC Web of Conferences, vol. 120, article 08003, 2017.

[40] A. M. Yusop, R. Mohamed, and A. Ayob, "Model building of thermoelectric generator exposed to dynamic transient sources," IOP Conference Series: Materials Science and Engineering, vol. 53, p. , 2013012015, 2013.

[41] H. S. Kim, W. Liu, G. Chen, C. W. Chu, and Z. Ren, "Relationship between thermoelectric figure of merit and energy conversion efficiency," Proceedings of the National Academy of Sciences, vol. 112, no. 27, pp. 8205-8210, 2015.

[42] H. A. Madkhali, A. Hamil, and H. Lee, "Validation, optimization and simulation of a solar thermoelectric generator model," Journal of Electronic Materials, vol. 46, no. 12, pp. 6756-6768, 2017.

[43] J. Chen, K. Li, C. Liu et al., "Enhanced efficiency of thermoelectric generator by optimizing mechanical and electrical structures," Energies, vol. 10, no. 9, p. 1329, 2017.

[44] M. Hong, K. Zheng, W. Lyv et al., Computer-aided Design of High-efficiency GeTe-based Thermoelectric Devices, Energy \& Environmental Science, London, UK, 2020.

[45] W. D. Liu, L. Yang, Z. G. Chen, and J. Zou, "Promising and eco-friendly Cu2X-based thermoelectric materials: progress and applications," Advanced Materials, vol. 32, no. 8, p. 1905703, 2020.

[46] P. Qiu, T. Mao, Z. Huang et al., "High-efficiency and stable thermoelectric module based on liquid-like materials," Joule, vol. 3, no. 6, pp. 1538-1548, 2019.

[47] W. He, G. Zhang, X. Zhang, J. Ji, G. Li, and X. Zhao, "Recent development and application of thermoelectric generator and cooler," Applied Energy, vol. 143, pp. 1-25, 2015.

[48] E. Müller, K. Zabrocki, C. Goupil, G. J. Snyder, and W. Seifert, "Functionally graded thermoelectric generator and cooler elements," in Materials, Preparation, and Characterization in Thermoelectrics, CRC Press, 2017.

[49] X. L. Shi, X. Tao, J. Zou, and Z. G. Chen, "High-performance thermoelectric SnSe: aqueous synthesis, innovations and challenges," Advanced Science, vol. 7, no. 7, p. 1902923, 2020.

[50] H. Mamur and Y. Çoban, "Detailed modeling of a thermoelectric generator for maximum power point tracking," Turkish Journal of Electrical Engineering \& Computer Sciences., vol. 28, no. 1, pp. 124-139, 2020.
[51] J. L. Wang, J. Y. Wu, and C. Y. Zheng, "Simulation and evaluation of a CCHP system with exhaust gas deep-recovery and thermoelectric generator," Energy Conversion and Management, vol. 86, pp. 992-1000, 2014.

[52] M. Hong, W. Lyu, Y. Wang, J. Zou, and Z. G. Chen, "Establishing the golden range of Seebeck coefficient for maximizing thermoelectric performance," American Chemical Society, vol. 142, no. 5, pp. 2672-2681, 2020. 